ISSN 0819-2642

ISBN 0734026420

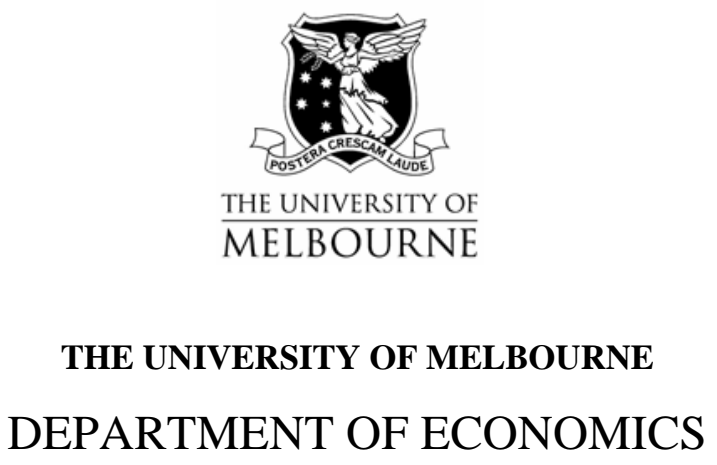

RESEARCH PAPER NUMBER 984

JANUARY 2007

Corporation Tax Revenue Growth in the UK:

A Microsimulation Analysis

by

John Creedy

\&

Norman Gemmell

Department of Economics The University of Melbourne Melbourne Victoria 3010 Australia. 


\title{
Corporation Tax Revenue Growth in the UK: A Microsimulation Analysis*
}

\author{
John Creedy* and Norman Gemmell** \\ * The University of Melbourne; ** Nottingham University
}

\begin{abstract}
This paper examines the built-in flexibility properties - as measured by the elasticity of revenue with respect to profits - of the UK corporation tax system. Emphasis is placed on determining some of the major influences on the extent to which total corporation tax revenue changes when profits change over the economic cycle. A microsimulation model, CorpSim, is constructed and used to obtain numerical results. In the model, corporations use group relief, capital allowances and losses in a tax-minimising manner. The growth of aggregate corporation tax revenue in practice in the UK appears to be highly volatile in relation to the growth of profits. High volatility in revenue elasticities is found to be especially associated with economic downturns. In mild economic downturns, corporation tax revenue elasticities may rise (because tax growth falls less than profit growth), but in more severe downturns, large but temporary decreases in revenue elasticities (and even negative elasticities) can be expected.
\end{abstract}

*This research was conducted while Norman Gemmell was at HM Revenue \& Customs' Analysis department. We are grateful to colleagues there for their support of this research, especially David Ulph and Edwin Ko. The views expressed in this paper are those of the authors and do not necessarily reflect those of HMRC. We are grateful for comments from participants at presentations at HMRC, HM Treasury and the New Zealand Treasury and Inland Revenue Department. 


\section{Introduction}

The purpose of this paper is to examine the built-in flexibility properties - as measured by the elasticity of revenue with respect to profits - of the UK corporation tax system. Emphasis is placed on determining some of the major influences on the extent to which total corporation tax revenue changes when profits change over the economic cycle. This exercise is motivated by the fact that it has proved to be extremely difficult to provide reliable forecasts of UK corporate tax revenues in recent years, in part because the underlying revenue properties of the tax are not well understood. It is important to understand the elasticity or built-in flexibility properties of the corporation tax system, in order to be able to distinguish their effects from those of discretionary changes in tax rates and thresholds, or other factors affecting tax revenues such as changes in avoidance and evasion. ${ }^{1}$ Section 2 briefly discusses the concepts of buoyancy and elasticity. In a theoretical analysis of the tax structure, Creedy and Gemmell (2006a) showed that, in priciple, the revenue elasticity may vary considerably over the economic cycle. The present paper extends that work by obtaining numerical orders of magnitude.

Given the complexity of corporation tax regulations and the structure of companies, combined with the paucity of data relating to the distribution of profits in the UK, the approach taken is to construct a simplified microsimulation model. Although the model abstracts from a number of the complexities, it is suggested that it nevertheless captures the essential characteristics of the system. This model is referred to as CorpSim. The approach contrasts with aggregate corporate tax revenue forecasting models based on time-series regression analyses which generally cannot separate the built-in effects on revenues from those due to other factors such as discretionary actions.

The approach may be contrasted with standard tax microsimulation models of households, used to examine revenue and distributional implications of income taxes and a range of transfer payments. These models are typi-

\footnotetext{
${ }^{1}$ For example, Devereux et al. (2004) considered the fact that corporate tax revenues have remained high despite periodic decreases in the statutory tax rate. They attribute this largely to growth in financial companies' profits.
} 
cally based on a large cross-sectional survey, providing sufficient information about each individual and household so that tax liabilities and eligibility for transfer payments can be determined reasonably accurately given gross incomes. ${ }^{2}$ In the present context, a considerable challenge arises from the need to model the transformation, for each corporation, between gross profits and taxable profits.

Microsimulation models of corporation tax must be able to capture the complex interplay between the liability conditions contained within the tax code, and company choices allowable under that code. An important dynamic element is involved. For example, it is necessary to model company choices of precisely when to claim various allowances against tax and how to share these allowances across companies within the same group. Of necessity, a model of corporate taxes must therefore contain a dynamic component relating to changes in profits over time, in view of the crucial role played by the ability to carry unclaimed losses and capital allowances into the future.

Any model which seeks to explain how corporation tax revenue changes over time requires, at a minimum, three main components. These are an initial distribution of profits for a population of firms, a method of adjusting each firm's profits over time and a method for computing the deductions against profits for each firm in each year. The way in which profits are modelled within CorpSim is described briefly in section 3 (with further details in Appendix B).This component generates the changing distribution of profits over time for a sample of corporations: for convenience, in what follows the term 'firm' is used instead of 'corporation' here. The model is restricted to two domestic sources of profit for each firm, and complications arising from international transactions are ignored. ${ }^{3}$

Section 4 describes how deductions, in the form of losses and capital allowances arising from investment, are used in the model to offset corporation tax. These generate the total taxable or net profits of a firm, given gross prof-

\footnotetext{
${ }^{2}$ However, variations in benefit take-up rates can introduce a difference between actual net incomes and those arising in priciple.

${ }^{3}$ This is not meant to imply that international aspects are unimportant, simply that they cannot easily be incorporated into the present simulation model. A useful extension would allow for the effect of tax on firms' behaviour in an international context.
} 
its from the two sources. In this section, attention is restricted to the case of a single firm in isolation. Section 5 turns to the consideration of firms within groups, involving the introduction of group relief. The modelling of the use of deductions is considerably more complex in this context compared with that of a single firm, in view of the much larger number of possibilities. The microsimulation model developed here uses a search algorithm designed to produce, for each firm, the minimum taxable profit in each period. ${ }^{4}$ However, no attempt is made to model the endogenous formation of groups.

Having described the structure of CorpSim, some results from applying the simulation model to a variety of scenarios are discussed in section 6. These provide useful insights into the revenue elasticity properties of corporation tax over the economic cycle and reveal strong similarities to the observed buoyancy of corporation tax liabilities in recent years. Section 7 discusses revenue elasticities over the long run. Results are summarised and conclusions drawn in section 8 .

The simulation model, as presently constructed, does not incorporate behavioural responses in the sense that the time profile of firms' gross profits, and hence losses, are exogenously determined. Capital allowances in turn depend on the time profile of profits from the two sources, given the assumed form of investment function used in the model. Groups of firms minimise their tax liabilities given the exogenous values of those variables. This is reasonable where the primary focus of the simulations is to examine corporation tax revenues for given tax rates and allowances. Nevertheless, the present model is capable of investigating the revenue consequences of changes in these tax parameters, and provides a 'no response' benchmark against which behavioural simulations could be compared.

\section{Tax Buoyancy and Elasticity}

Tax buoyancy measures the observed percentage change in tax revenues divided by the percentage change in the tax base. Buoyancy is affected both by

\footnotetext{
${ }^{4} \mathrm{~A}$ simpler set of rules of thumb is considered in Appendix C, and compared with the 'tax minimising' approach.
} 
Table 1: UK Corporation Tax Buoyancy, Tax and Profit Growth: 1992-2003

\begin{tabular}{rrrr}
\hline Year & $\begin{array}{c}\text { Tax } \\
\text { growth }(\%)\end{array}$ & $\begin{array}{c}\text { Profit } \\
\text { growth }(\%)\end{array}$ & Buoyancy \\
\hline 1992 & 4 & 6 & 0.7 \\
1993 & 33 & 19 & 1.8 \\
1994 & 30 & 4 & 7.5 \\
1995 & 12 & 12 & 1.0 \\
1996 & 7 & -1 & -5.8 \\
1997 & 0.4 & 7 & 0.1 \\
1998 & 12 & 9 & 1.2 \\
1999 & 11 & -2 & -7.3 \\
2000 & 10 & 16 & 0.6 \\
2001 & -13 & -4 & 3.3 \\
2002 & 4 & -0.1 & -36.0 \\
2003 & 7 & 6 & 1.1 \\
2004 & 22 & 18 & 1.2 \\
\hline
\end{tabular}

the built-in properties of the tax structure and by any changes in any other factors, such as changes in tax parameters or compliance, which alter the relationship between the tax base and revenues raised from that base. The automatic revenue growth, associated with these built-in properties - fiscal drag - is a familiar feature of progressive income taxes where the existence of fixed or income-related tax allowances and rising marginal tax rates generate a rising share of total income paid in income tax as average incomes rise. It can be measured in unit-free terms by the revenue elasticity of a tax the automatic percentage change in tax revenues divided by the percentage change in the tax base. For progressive taxes this elasticity exceeds one, because revenues rise proportionately faster than the tax base. The difference between buoyancy and elasticity therefore provides a measure of the impact of changes in discretionary and other exgonous factors (such as compliance) on tax revenues.

Table 1 shows annual gross profit and corporation tax growth rates, and the resulting revenue buoyancy, in the UK since $1992 .^{5}$ This shows that

\footnotetext{
${ }^{5}$ These data, from HMRC National Statistics, Table 11.2, are for corporation tax accruals in each fiscal year (beginning on 05 April), for on-shore companies, excluding life
} 
annual tax and profit growth rates are highly volatile. Buoyancy is also highly volatile, because tax and profit growth rates follow quite different patterns over time. A key objective of the simulation analysis in later sections is, therefore, to identify how far this observed volatility in corporation tax buoyancy is also generated by simulations of automatic responses as captured by the revenue elasticity.

\section{A Model of Profits}

This section provides a brief outline of the gross profit component of CorpSim; further details are in Appendix B. The dynamic component contains both systematic and stochastic elements, and is designed to generate changes in the distribution of profits over time by tracing the profits of each of a large number of firms over a required time period. Standard stochastic models of income distribution cannot be used because, unlike income, profits are negative for many firms. The approach used here involves an assumption that there is some minimum profit (maximum negative profit) below which firms cannot go in any year. ${ }^{6}$

In practice, firms can earn profits from several sources which are taxed under different schedules. The corporation tax rules generally limit the extent to which losses or other deductions available under one schedule can be offset against others. However, aggregate data suggest that total UK-source profit is dominated by two income sources: trading profits and profits arising from loan-relationships (interest income). ${ }^{7}$ This section therefore models two profit sources and subsequently models deductions against those profits based on the corporation tax rules applying to trading and loan-relationship profits.

assurance companies. see http://www.hmrc.gov.uk/stats/corporate_tax/table11_2.pdf.

${ }^{6}$ CorpSim does not allow for 'births' and 'deaths' of firms (or shifts into or out of the tax jurisdiction), but considers a fixed population over a given time period.

${ }^{7}$ Data for 2003-04 show that in aggregate across financial and non-financial sectors (excluding North Sea oil, and life assurance) gross trading profits accounted for around 77 per cent of total UK-source gross profits with loan relationship income accounting for a further 16 per cent. When foreign-source income is included the former two profit sources account for around 75 per cent of total gross profit. 
Suppose that profit in year $t$ is $P_{t}$ where $-d_{t}<P_{t}<\infty$. The subscript $i$, whereby profit is $P_{i, t}$ for the $i$ th firm, has been omitted for convenience. The application of a common, positive annual rate of growth of profits to all firms, without special allowance for the fact that some have negative $P_{t}$, would involve those with positive profits moving, as a group, away from those with negative profits. To avoid this implausible situation, the approach adopted here is first to convert profits into a positive variable, $x_{t}$, where:

$$
x_{t}=P_{t}+d_{t}
$$

The variable $x_{t}$ is subject to a growth rate made up of a systematic component, $g_{t}$, and a random component, $u_{t}$. The $t$ subscript on $g$ allows the systematic growth of profits to vary in some way over time, along with the minimum profit. Thus $x$ is specified to change according to:

$$
x_{t}=x_{t-1}\left(1+g_{t}+u_{t}\right)
$$

Furthermore, some 'persistence' in growth rates, for example if 'success breeds success', is allowed such that:

$$
u_{t}=\gamma u_{t-1}+v_{t}
$$

and $v$ is assumed to be Normally distributed as $N\left(0, \sigma_{v}^{2}\right)$.

Substituting (1) into (2) gives:

$$
P_{t}=P_{t-1}\left(1+g_{t}+u_{t}\right)-\left(d_{t}-d_{t-1}\right)+d_{t-1}\left(g_{t}+u_{t}\right)
$$

The growth rate, $g_{t}$, is composed of a constant component, $g^{*}$, representing inflation and/or trend real growth, and a real cyclical component, $g_{t}^{c}$. This cyclical aspect can be described by an amplitude of $a_{g}$ and a wavelength of $w_{g}$. Similarly, suppose that the proportional rate of change in $d$ (the maximum loss) from one period to the next consists of a fixed term, $\dot{d}^{*}$, and a cyclical component, $\dot{d}_{t}^{c}$. Thus:

$$
d_{t}=d_{t-1}\left(1+\dot{d}^{*}+\dot{d}_{t}^{c}\right)
$$

The cyclical component has an amplitude of $a_{d}$ and a wavelength of $w_{d}$. This captures the notion that the extent of maximum losses can also behave 
cyclically; for example, in a recession when profit growth is lower on average, maximum losses are likely to become larger.

The above specification is extended (as shown in Appendix B) to the case where firms obtain profits from two sources, denoted $A$ and $B$. These two income sources give rise to profits of $P^{A}$ and $P^{B}$, with corresponding values of $x_{A}=P^{A}+d^{A}$ and $x_{B}=P^{B}+d^{B}$. Starting from a given initial joint distribution of profits, such that there is some correlation, $\rho$, between $A$ and $B$ profits, it is possible to generate profit flows in subsequent periods.

In the 'benchmark' simulation case examined below, the initial maximum loss is set to $£ 600 \mathrm{k}$ for $A$ and $B$ and is assumed to follow the same pattern as the systematic components of $A$ and $B$ profits. These have a 2 per cent trend growth with a 0.5 per cent cyclical amplitude, and a wavelength (that is a complete cycle) of 10 years. However, the cycles for $d^{A}$ and $d^{B}$ are 'shifted' relative to the profit growth rate cycles so that the cyclical components of $d^{A}$ and $d^{B}$ move inversely with the profit cycles. That is, they are increasing (implying larger maximum losses where relevant) when the cyclical components of profits are decreasing.

\section{Simulating Deductions: Single Firms}

In addition to the profit generating components of CorpSim, a crucial component consists of a mechanism for determining the way in which firms use their losses and capital allowances to transform their total gross profit (that is, profits from both income sources) into taxable, or net, profit. Given taxable profit for each firm, it is then a simple matter to apply the UK corporation tax structure. The details of the structure, involving its rates and threstholds, are described in Appendix A. The situation facing a single firm is very much simpler than that facing firms within a group. The model used to examine single firms is called CorpSim-S, while that used to examine firms within groups is called CorpSim-G.

This section discusses the way in which the total net profit, that is profit after all deductions, of a single firm is calculated in CorpSim-S. Consider a firm which, as above, receives profit from two sources $A$ and $B$ in period $t$ 
of $P_{t}^{A}$ and $P_{t}^{B}$ respectively. Total gross profit, $P_{t}$, is thus:

$$
P_{t}=P_{t}^{A}+P_{t}^{B}
$$

It is necessary to transform total gross profit into total net profit by subtracting any capital allowances and losses. In practice, the use of such deductions by a firm may depend on its expectations regarding future profits and losses arising from the two sources. However, without a clear view of, and indeed information about, the main determinants of expected future profits, the present model abstracts from the consideration of profit expectations. The use of capital allowances is described in subsection 4.1 and the use of losses is examined in subsection 4.2. The way in which priorities in making deductions are modelled is then described in subsection 4.3. An illustrative example is provided in subsection 4.4.

\subsection{Capital Allowances}

Capital allowances are calculated using fiscal depreciation rules applied to firms' investment expenditures, which requires these expenditures to be specified. The capital allowances generated from investment are assumed to arise entirely in association with the firm's trade and hence are deductible from trading profits. This reflects the vast majority of investment expenditure for which firms claim capital allowances in practice. However, the level of investment expenditure undertaken by firms may be determined by a number of variables, among which the firm's various sources of profits are likely to be important. Capital allowances are used to off-set $A$ profits, and any 'excess' capital allowances may be used to off-set $B$ profits.

Let $I_{t}$ denote investment in period $t$. The model assumes that investment is a simple function of both $A$ and $B$ profits such that:

$$
I_{t}=\alpha+\beta\left[\theta\left(P_{t}^{A}+\phi P_{t}^{B}\right)+(1-\theta)\left(P_{t-1}^{A}+\phi P_{t-1}^{B}\right)\right]
$$

Hence, investment is a linear function of the weighted average of the current and previous period's weighted sum of profits from the two sources. These weights can be specified to reflect alternative views regarding the relative 
importance of different profit sources or time horizons in the determination of investment. With $\beta, \phi>0$, the specification in (7) allows for investment to be positively related to either or both types of profit and for a limited lagged response. If $\phi=0$, only trading profits determine investment, and $\theta=1$ implies only current profits are relevant, while $\theta=0$ implies that only lagged profits affect investment.

Capital allowances depend on investment by the firm and the fiscal depreciation regime. In the UK, the fiscal depreciation rules for plant and machinery investment, and investment in industrial buildings, are different. The former are depreciated on a writing-down basis at a rate of 25 per cent per year, while the latter are depreciated on a straight-line basis over 25 years. However, plant and machinery investment dominates capital allowances empirically and, for this reason, only this is modelled below.

With investment in period $t$ of $I_{t}$, capital allowances available in period $t$ are denoted, $C A_{t}^{A}$. The $A$ superscript in this terms reflects the fact that capital allowances relate to $A$-source profits. Where $\delta=0.25$ is the depreciation rate, allowances are given by:

$$
\begin{aligned}
C A_{t}^{A} & =\delta I_{t}+\delta(1-\delta) I_{t-1}+\delta(1-\delta)^{2} I_{t-2}+\ldots \\
& =\delta\left(I_{t}+C P_{t-1}^{A}\right)
\end{aligned}
$$

where $C P_{t-1}^{A}=\delta(1-\delta) I_{t-1}+\delta(1-\delta)^{2} I_{t-2}+\ldots$ is the pool of capital allowances available at period $t$, arising from previous periods' investments. ${ }^{8}$ If there are insufficient $A$ profits against which to claim capital allowances, 'excess' capital allowances, $X C A_{t}$, are said to arise. These may be deducted from $B$ profits. Alternatively they may be used to generate a trading loss, such that $P_{t}^{A}-C A_{t}^{A}<0$, which is then added to the $A$ loss pool, $L P_{t}^{A}$, to be carried forward to the next period. How firms choose between these alternatives is specified below. The capital allowance pool available at the end of period $t$, to be carried forward, is given by:

$$
C P_{t}^{A}=(1-\delta)\left\{C P_{t-1}^{A}+I_{t}\right\}
$$

${ }^{8}$ The present analysis abstracts from the phenomenon of capital allowance 'disclaiming' in which some firms postpone claims for capital allowances, such that $\delta_{i}<0.25$. 


\subsection{The Use of Losses}

If a firm makes a loss in period $t$, such that $L_{t}^{A}=-P_{t}^{A}>0$ or $L_{t}^{B}=-P_{t}^{B}>0$, these may be claimed concurrently against $P_{t}^{B}$ or $P_{t}^{A}$. Alternatively, they may be carried forward and claimed against future profits of the same source. As a result, in any given period, $t$, there may be loss pools from the previous period, denoted $L P_{t-1}^{A}$ and $L P_{t-1}^{B}$, which are available to offset current $A$ and $B$ profits respectively. Group relief of losses, where there are two firms in a group, is considered in section 5 .

The corporation tax rules used for modelling loss use are shown in Table 2. These are the rules governing trading and loan-relationship losses used in practice, with the exception that carrying back of losses is omitted from the model.

Table 2: Corporation Tax Rules and the Use of Losses

\begin{tabular}{|c|c|c|c|c|c|}
\hline \multirow{2}{*}{$\begin{array}{l}\text { Profit } \\
\text { source }\end{array}$} & \multicolumn{2}{|c|}{ Used in-year against: } & \multirow{2}{*}{$\begin{array}{l}\text { Group- } \\
\text { relieved } \\
\text { in-year }\end{array}$} & \multicolumn{2}{|c|}{ Carried forward: } \\
\hline & $\begin{array}{l}\text { same } \\
\text { source }\end{array}$ & $\begin{array}{l}\text { other } \\
\text { source }\end{array}$ & & $\begin{array}{l}\text { within } \\
\text { source }\end{array}$ & $\begin{array}{l}\text { across } \\
\text { source }\end{array}$ \\
\hline$A$ : Trading & Yes & Yes & Yes & Yes & No \\
\hline$B$ : Loan-relationship & Yes & Yes & Yes & Yes & No \\
\hline
\end{tabular}

\subsection{Priorities in Claiming Deductions}

The order in which deductions are claimed against gross profits is determined in part by the corporation tax rules and in part by firms' choices. In the simplified model here, where there are only two profit sources, capital allowances are first deducted from $A$ profits. In the absence of disclaiming, this order is dictated by the tax code. Whether any excess capital allowances should be carried forward as an $A$ loss, or used currently against $B$ profits is a choice allowable under the tax code. ${ }^{9}$ Clearly, the use of excess allowances to offset $B$ profits is more likely if expectations of future $A$ profits are low and current

\footnotetext{
${ }^{9}$ The size and type of losses brought forward from previous periods may also be relevant to this decision.
} 
$B$ profits are high. In the absence of any information on profit expectations, the current model assumes that all firms prefer to offset any current losses or excess capital allowances against any currently available profits, rather than carry them forward to future periods when they can no longer be used across profit sources. This reflects a view that the expected net present value of current losses and capital allowances (as profit offsets) is greater in the current period. If a firm faces a choice, its ability to claim deductions, and the order in which they are claimed, depend on the size and source of its profits.

Table 3 shows the assumed order (moving down the table) in which deductions are claimed for the four possible combinations of profits and losses for $A$ and $B$ for a single firm $i$. The more complex choices when two firm's form a group are discussed in section 5 below.

Table 3: Profit Combinations for a Single Firm

\begin{tabular}{lll}
\hline Profit combination & \multicolumn{2}{c}{ Profit source } \\
\cline { 2 - 3 } & $A$ & $B$ \\
\hline$P_{i}^{A}>0 ; P_{i}^{B}>0$ & $C A_{t}$ & \\
& $L A_{t-1}$ & $X C A_{t}$ \\
& & $L B_{t-1}$ \\
\hline$P_{i}^{A}>0 ; P_{i}^{B}<0$ & $C A_{t}$ & \\
& $L B_{t}$ \\
& $L A_{t-1}$ \\
\hline$P_{i}^{A}<0 ; P_{i}^{B}>0$ & \multicolumn{2}{c}{$X C A_{t}$} \\
& & $L A_{t}$ \\
& & $L B_{t-1}$ \\
\hline$P_{i}^{A}<0 ; P_{i}^{B}<0$ & - & - \\
\hline
\end{tabular}

Table 3 shows that, in general, the order in which deductions are claimed is as follows. First, capital allowances are claimed against $A$ profits, with any excess capital allowances then claimed against $B$. Second, current $A$ or $B$ losses $\left(L A_{t}, L B_{t}\right)$ are claimed against current profits across sources. Third, past losses are brought forward and used within source. 


\subsection{An Illustrative Example}

Table 12 provides an example of how net profits are calculated in CorpSim$\mathbf{S}$, where only single firms are considered. This shows two firms, $i$ and $j$, where the former makes positive $A$ and $B$ profits in year $t$, while the latter makes an $A$ loss of $£ 800$. The two firms also have loss pools brought forward from previous periods as shown in square brackets below line 1, and capital allowances given in line 2 . The method for calculating net profits first deducts capital allowances from $A$ profits, where possible.

Table 4: Illustrative Net Profit Calculation: Single Firms

\begin{tabular}{lcccc}
\hline \multicolumn{1}{c}{ Profits: } & $\begin{array}{c}\mathrm{A}: \\
\text { Trading }\end{array}$ & $\begin{array}{c}\mathrm{B}: \\
\text { Non-trading }\end{array}$ & $\begin{array}{c}\mathrm{A}: \\
\text { Trading }\end{array}$ & $\begin{array}{c}\mathrm{B}: \\
\text { Non-trading }\end{array}$ \\
\hline 1. Gross Profit & 1100 & 500 & -800 & 150 \\
[Loss pool:LP $\mathrm{t}_{\mathrm{t}-1}$ ] & {$[5000]$} & {$[200]$} & {$[100]$} & {$[100]$} \\
2. Less Cap. Allow & -100 & & -50 & $\rightarrow$ \\
3. = 1. minus 2. & 1000 & 500 & -800 & 100 \\
4. Less $\mathrm{L}_{\mathrm{t}}$ & - & - & - & -100 \\
5. Less LP & -1000 & -200 & - & 0 \\
\hline 6. Net Profit & 0 & $\mathbf{3 0 0}$ & $\downarrow$ & 0 \\
7. [Loss Pool:LP & {$[4000]$} & {$[0]$} & {$[800]$} & {$[100]$} \\
\hline
\end{tabular}

For firm $j$ the $A$ loss means that excess capital allowances are carried across and deducted from $B$ profits (of £150), yielding line 3 . As line 4 shows, $£ 100$ of current losses are then deducted from $j$ 's $B$ profits (after capital allowances) to yield zero net $B$ profits, shown in line 6 . The remaining $£ 700$ of current $A$ losses are added to the $£ 100 A$ loss pool from previous periods to give a current $A$ loss pool of $£ 800$, as in line 7 . Past $B$ losses of $£ 100$ are also carried forward, in line 7 . For firm $i$, having no current losses, past losses can immediately be deducted from profits (after capital allowances) to yield net $A$ profits of zero and net $B$ profits of $£ 300$ (line 6 ). Remaining losses in the loss pool are carried forward (line 7). 


\section{Simulating Deductions: Groups}

This section describes the procedure used in CorpSim-G where single firms join to form groups, but individual firms continue to be taxed on an unconsolidated basis. The UK corporation tax system permits firms' losses and excess capital allowances to be used as deductions against the profits of group members with positive gross profits. This takes the form of group relief, which is surrendered by group loss-makers to partners in profit. The corporate tax base is composed of many single firms and also many multifirm groups, where there can be as many as hundreds of firms in one group. Modelling the group relief associated with this complex type of multi-firm group is beyond the scope of the present model.

CorpSim-G models a population of firms which are assumed to form groups consisting of pairs of firms. Although having only two members of a group may seem restrictive, the key analytical aspect of group relief for present purposes is that members of a group with losses can surrender (all or some of) those losses to members with positive profits. The two group members represented in the model can therefore be thought of as capturing the sum of loss-making group members in practice and similarly for profitmakers. This method therefore captures the essential characteristic of group relief, whereby losses can only be carried across firms contemporaneously. To simplify the analysis, group relief of excess capital allowances is not considered. The priorities in claiming group deductions are discussed in subsection 5.1 and an example for two hypothetical firms in a group is provided in subsection 5.2.

\subsection{Priorities in Claiming Group Deductions}

Modelling firms' priorities in claiming deductions within groups is substantially complicated by the number of profit and loss combinations, even with only two profit sources and two firms in a group. In this simple case there are nevertheless 16 possible arrangements of profits and losses associated with $A$ 
and $B$ profit sources. These are shown in Table $5 .{ }^{10}$

Table 5: Profit Combinations: Two Firms

\begin{tabular}{lllll}
\hline Combination & $P_{i}^{A}$ & $P_{i}^{B}$ & $P_{j}^{A}$ & $P_{j}^{B}$ \\
\hline 1 & $>0$ & $>0$ & $>0$ & $>0$ \\
2 & $>0$ & $>0$ & $>0$ & $<0$ \\
3 & $>0$ & $>0$ & $<0$ & $>0$ \\
4 & $>0$ & $>0$ & $<0$ & $<0$ \\
\hline 5 & $>0$ & $<0$ & $>0$ & $>0$ \\
6 & $>0$ & $<0$ & $>0$ & $<0$ \\
7 & $>0$ & $<0$ & $<0$ & $>0$ \\
8 & $>0$ & $<0$ & $<0$ & $<0$ \\
\hline 9 & $<0$ & $>0$ & $>0$ & $>0$ \\
10 & $<0$ & $>0$ & $>0$ & $<0$ \\
11 & $<0$ & $>0$ & $<0$ & $>0$ \\
12 & $<0$ & $>0$ & $<0$ & $<0$ \\
\hline 13 & $<0$ & $<0$ & $>0$ & $>0$ \\
14 & $<0$ & $<0$ & $>0$ & $<0$ \\
15 & $<0$ & $<0$ & $<0$ & $>0$ \\
16 & $<0$ & $<0$ & $<0$ & $<0$ \\
\hline
\end{tabular}

The order in which deductions are assumed to be claimed for the group case within CorpSim-G is as follows. First, as for single firms, capital allowances are deducted within firms (wherever possible) including excess capital allowances claimed across $B$ profits (where there are insufficient $A$ profits). Since current losses can only be group-relived if surrendered or received concurrently, these are deducted next. However it might be expected that groups would wish to use losses (both current and past) in a tax minimising manner. This is likely to be affected by various business factors unrelated to taxation and by the tax consequences of expectations regarding future profits and losses; for example by shifting losses out of companies where they are expected to be stranded for some time. As with single firms,

\footnotetext{
${ }^{10}$ With only one firm, Table 3 showed 4 combinations, equivalent to rows $1,5,9$, and 13 in Table 5. With an additional firm, for each of these first 4 combinations, there are a further 4 combinations for the second firm. However, the following rows are equivalent if $i$ and $j$ are reversed: $2=5 ; 3=9 ; 4=13 ; 10=7 ; 8=14 ; 12=15$. Hence 10 different cases need to be considered.
} 
the model abstracts from profit expectations by groups. However, it is still the case that groups are likely to be faced with choices over the use of past and current losses, within and between members, which affect the group's overall tax liability.

The simulation model therefore employs a search procedure which seeks to deduct losses (from profits net of capital allowances) such that both current and past losses are used in ways that minimise current net profits within the group, and any remaining losses to be carried forward. For example, group net profits may be reduced to zero via a number of alternative allocations of losses, but some of these involve greater use of past losses than others (fewer stranded losses). The search procedure used allocates losses within and between firms to ensure that the option with minimum group net profits and least stranded losses is achieved. Minimisation of group net profits does not guarantee tax minimisation, for example, if one small group member is taxed at 19 per cent whilst the other is taxed at 30 per cent. However, with the exception of these rare cases, tax minimisation can generally be presumed from this procedure. ${ }^{11}$

\subsection{An Illustrative Example}

Table 13 repeats the illustration for single firms in Table 12, but for the case where firms $i$ and $j$ are in a group. This configuration of profits corresponds to case 3 in Table 5. Gross profits, loss pools and capital allowances in year $t$ are as in the previous example. Capital allowances are again deducted first to give profits, net of capital allowances, shown in line 3 .

The issue for the group is how to allocate the $£ 800 A$-loss in firm $j$ to minimise group net profits. These could all be allocated to reduce $i$ 's $A$ profits (of $£ 1000$ in line 3 ) but because $i$ also has a large $A$ loss pool from

\footnotetext{
${ }^{11}$ An alternative version of CorpSim-G takes a somewhat more mechanical view of the use of deductions. In this version, deductions are subtracted from profits in a fixed order, following a set of 'rules of thumb', rather than attempting to minimise group net profits. Deductions are subtracted in the following order: capital allowances, current losses deducted within firms, excess capital allowances, group relief, losses brought forward within firms from previous periods. Comparisons of elasticities using the alternative approaches are given in Appendix C.
} 
Table 6: Illustrative Net Profit Calculation: Groups

\begin{tabular}{|c|c|c|c|c|}
\hline & \multicolumn{2}{|c|}{ Firm $i$} & \multicolumn{2}{|c|}{ Firm $j$} \\
\hline Profits: & $\begin{array}{c}\text { A: } \\
\text { Trading }\end{array}$ & $\begin{array}{c}\mathrm{B}: \\
\text { Non-trading }\end{array}$ & $\begin{array}{c}\text { A: } \\
\text { Trading }\end{array}$ & $\begin{array}{c}\mathrm{B}: \\
\text { Non-trading }\end{array}$ \\
\hline 1. Gross Profit & 1100 & 500 & -800 & 150 \\
\hline [Loss pool:LP $\mathrm{LP}_{\mathrm{t}-1}$ ] & [5000] & [200] & [100] & [100] \\
\hline 2. Less Cap. Allow & -100 & - & -50 & $\rightarrow$ \\
\hline 3. $=1$. minus 2. & 1000 & 500 & -800 & 100 \\
\hline 4. Less $L_{t}$ & -200 & -500 & - & $=100$ \\
\hline 5. Less $L P_{t-1}$ & -800 & 0 & - & 0 \\
\hline 6. Net Profit & 0 & $\mathbf{0}$ & 0 & 0 \\
\hline 7. [Loss Pool:LP & [4200] & [200] & [100] & [100] \\
\hline
\end{tabular}

previous periods (£5000) this would leave $£ 4800$ of these stranded until a future period. ${ }^{12}$ As line 4 of Table 13 shows, by allocating the $£ 800$ loss in the way indicated, group net profits become zero, and the minimum possible loss pools (£4600) are carried forward to $t+1$. In the earlier single firm illustration, total net profits were positive and loss pools totalling $£ 4900$ were carried forward to $t+1$. This illustration therefore demonstrates the capacity for group formation to reduce both current tax liabilities and the time lag between the creation of losses and their use as profit off-sets. Both of these properties can affect the time-series profile of corporation tax revenues over the economic cycle. Further details of the procedure are given in Appendix D.

\section{Some Simulation Results}

This section presents some results from applying the simulation model CorpSim, described in previous sections. Emphasis is placed on the main summary statistic used to examine fiscal drag - the elasticity of aggregate corporation tax revenue with respect to changes in aggregate gross profits. There are many alternative scenarios which could be simulated, including differ-

\footnotetext{
${ }^{12}$ If $j$ 's losses of $£ 800$ are surrendered to off-set $i$ 's $A$ profits, only $£ 200$ of $i$ 's previous $A$ losses could be used in year $t$, to reduce $i$ 's net $A$ profits to zero.
} 
ent patterns of profit growth (for example different trend and cycle combinations), different degrees of randomness in the profit growth process and different assumptions regarding correlations both over time and across profit sources. In addition, the proportion of firms in groups could be changed, and the implications of alternative tax rates and thresholds could be investigated.

After briefly describing the simulation procedure in subsection 6.1 , this section begins in subsection 6.2 with the analysis of a benchmark case. It then compares outcomes for alternative values of the key parameters. Thus subsection 6.3 examines revenue elasticities resulting from larger economic cycles, and subsection 6.4 considers the implications of introducing relative movements in profits between firms. Subsection 6.5 decomposes the revenue elasticity into several components. Subsection 6.6 considers the importance of the 'small company rate' for the revenue elasticity.

\subsection{The Simulation Procedure}

After generating the initial profit distribution, the model is then simulated for 20 periods from $t=1$, which covers two complete cycles. ${ }^{13}$ When using CorpSim-S, the single firm case, 20k single firms are drawn from the initial gross $A$ and $B$ profit distributions. It then generates their gross profits for each of the 20 periods and applies eligible deductions to calculate their total taxable or net profits, and hence their corporation tax payments, by applying the appropriate corporation tax rate. Summing across all 20k firms in each period yields the value of total corporation tax payments which, together with the total profits from all firms, allows the revenue elasticity to be calculated using the year-to-year changes.

For CorpSim-G, the group case, a similar procedure is followed except that 10k firms are randomly drawn from each of two separate pairs of profit distributions (for $A$ and $B$ ). Selected firms from the first set of draws are then randomly paired with those from the second set. It would be possible to use a non-random pairing procedure but in the absence of clear guidance

\footnotetext{
${ }^{13}$ In fact, an initial 10 year period is simulated to allow capital allowances to reach a steady state as discussed below. All results reported below, and referred to as years 1 20, follow that initial 10 year period.
} 
from theory, or suitable data on the determinants of group membership, the random case provides a useful benchmark. This process essentially determines whether and when groups in the simulation are composed of two profit-makers, two loss-makers, and so on, and the extent of their joint profits or losses.

Firms' initial capital allowances are determined by their current investment (in turn determined from firms' profits using (7)) and their capital allowance pools. However, with no prior investment, this requires initial capital allowance pools to be specified. This is achieved by setting the ratio of the each firm's initial capital allowance pool to its total gross profit $\left(C P_{i, 1}^{A} /\left(P_{i, 1}^{A}+P_{i, 1}^{B}\right)\right)$ equal to $\beta$ in (7). This has the effect of ensuring that the ratio of the pool of capital allowances to profits available at $t=1$ is close to the ratio of capital allowances from new investment to profits. Without this assumption, there could be long transition periods until capital allowance pools reached a steady state.

\subsection{A Benchmark Case}

The following examples begin by considering a benchmark case and then examining variations around that case. Figure 1 shows the systematic pattern of the growth rate of average total profit (that is, the sum $P^{A}+P^{B}$ ) both for a relatively low cycle amplitude of 0.005 and for a medium amplitude cycle of 0.01 . The Figure shows 10-year cycles where the low amplitude generates a range of profit growth rates between +3.2 per cent and +0.8 per cent, around a trend of 2 per cent. The medium cycle generates higher growth at the top of the cycle $(+4.3$ per cent) and growth at the bottom of the cycle that is slightly negative. Both these cycles are examined in section 6 which also examines a high cycle amplitude of 0.015 , which generates profit growth rates in the range +5.5 per cent to -1.4 per cent. In fact, profit growth rates in practice can fluctuate over a much larger range than even the high-cycle case. The profit growth rates in Figure 1 arise from the combined effect of the assumed trend and cycle in profits, and the trend and cycle in the maximum loss. Profit growth rates of individual firms differ from those average rates to 


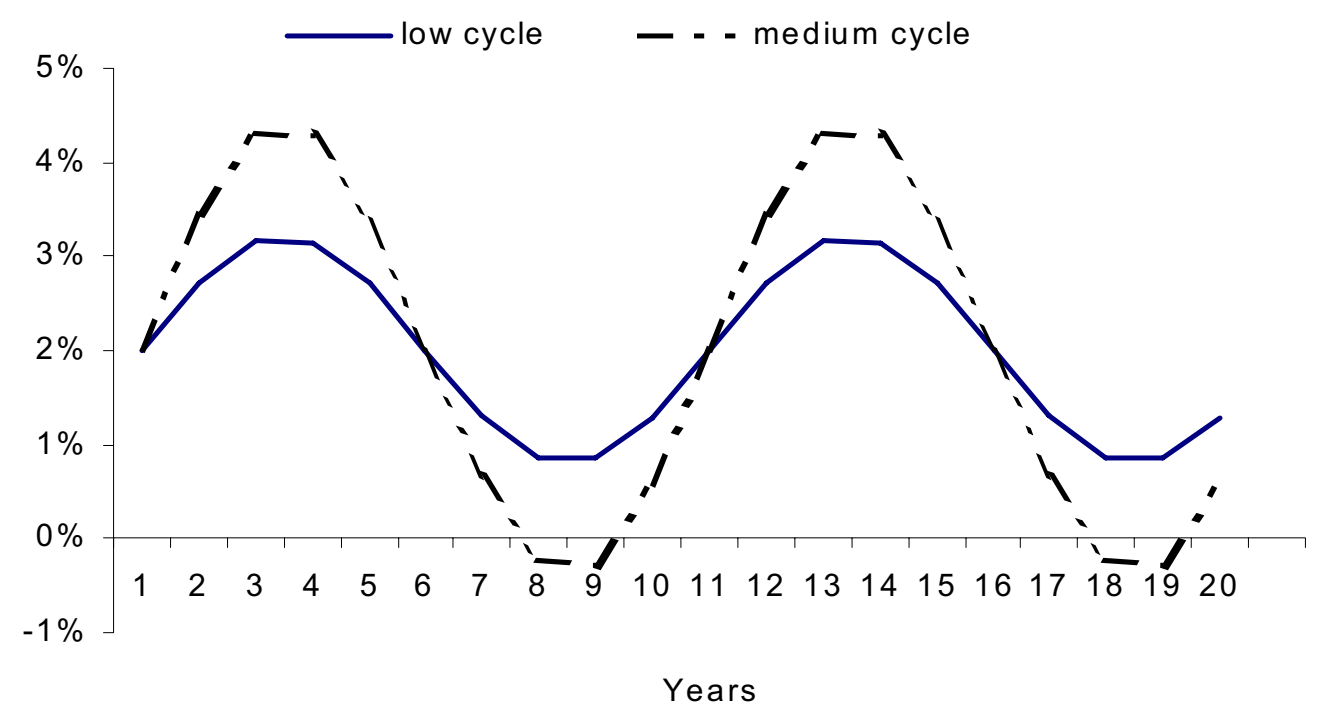

Figure 1: Simulated Profit Cycles

the extent that stochastic processes apply. In the absence of stochastics, all firms have the same growth rates and there are no relative changes in firms' profits.

Benchmark simulations use the low-cycle profit growth shown in Figure 1, and abstract from stochastic effects: $u_{i t}^{A}=u_{i t}^{A}=0$ in (18) and (19) in Appendix B. The profit parameters are given in Appendix B. Benchmark simulations assume a correlation between $A$ and $B$ profits of 0.05. Analysis of around 160k firms in the CT600 database for 2001-02 to 2003-04 produced correlation coefficients in the region of 0.3 to 0.4. Simulations examined include: $\rho=-0.05,0.0,0.05$ and 0.40 .

Benchmark values for the other parameters in (7) are set as follows: $\alpha=0$; $\beta=0.15$ (that is, investment is proportional to total current-plus-lagged profits); $\theta=0.5$ (that is, past and current profits affect investment equally); and $\phi=0.8$ (that is, $B$ profits take a weight 80 per cent of that for $A$ profits). These weights are not critical for the subsequent results reported, but can 


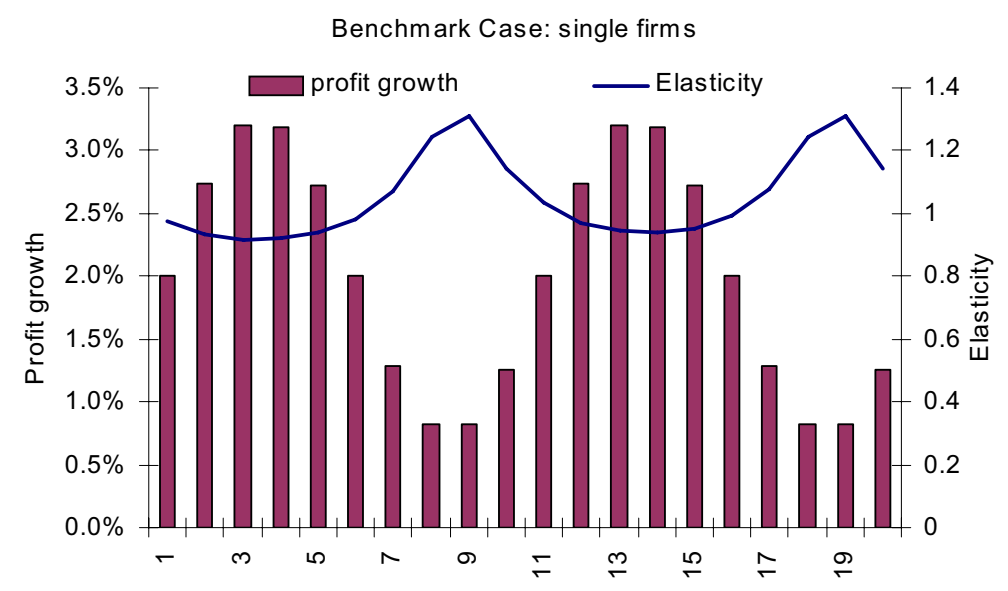

Figure 2: Benchmark Case, Single Firms

readily be altered.

Figure 2 shows profit growth and the revenue elasticity for the benchmark case of a low profit cycle ( 0.8 per cent to 3.2 per cent) and no stochastics, so that all firms move together over the economic cycle. It can be seen that the elasticity fluctuates in what appears to be a counter-cyclical manner, from a minimum of around 1 at high profit growth rates to a maximum of around 1.3 at the lowest point in the cycle. That is, tax growth is up to 30 per cent faster than profit growth at the bottom of the cycle and approximately equal to profit growth at the top of the cycle.

This result arises because when profit growth falls modestly below trend, the tendency for profits to fall relative to deductions serves to increase the elasticity; that is, tax growth falls proportionately less than profit growth. In this case the cycle is so weak (that is, it has a low amplitude) that the mild downturn causes few firms to move out of taxpaying status.

Figure 3 shows the tax and profit growth rates associated with the elasticities in Figure 2. This shows that the tax growth profile is a smoothed version of the profit growth profile. Thus tax growth is higher than profit growth at the bottom of the cycle. In understanding this result it is important to remember that total profits here are defined to include negative values (losses), consistent with National Accounting definitions, but unlike 


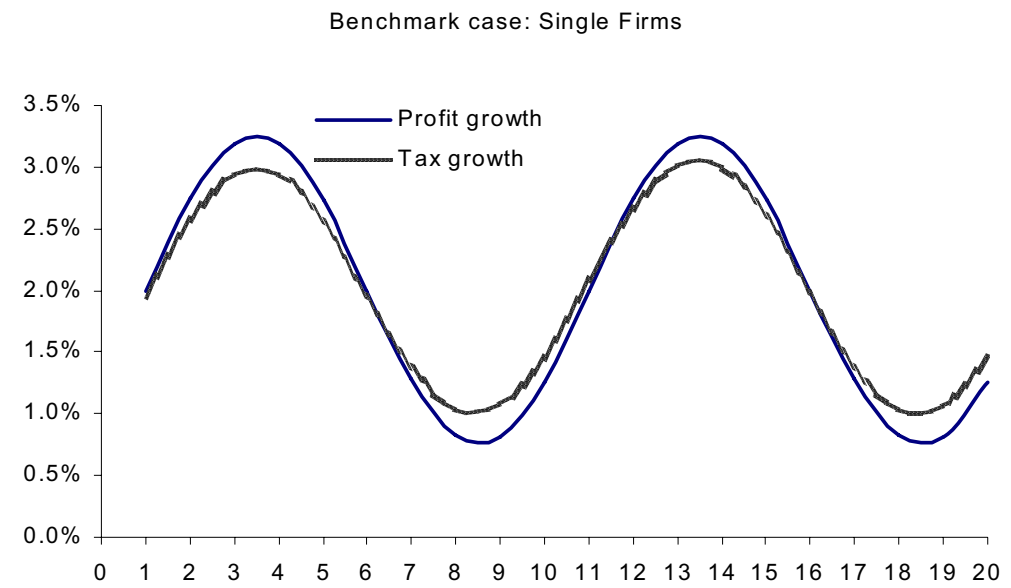

Figure 3: Benchmark: Tax \& Profit Growth

the usual HMRC definition of taxable profits. However, tax growth is driven by the growth of positive profit values, which tends to be somewhat more smooth.

Figure 4 compares the benchmark elasticity profile for the case where all firms are single with the case where all firms are in groups of two. The group case involves a smoother elasticity profile; in particular, the increase in the elasticity during downturns is less marked. This reflects the fact that, by using group losses contemporaneously to relieve group profits, groups' tax liabilities in aggregate move more in line with their profits (including losses) in aggregate than is possible for single firms.

\subsection{Elasticities with Larger Cycles}

The results in Figure 4 suggest relatively small elasticities. These are much smaller than the values observed for tax buoyancy, which result in part from the wide fluctuations in profit growth, ranging from almost 20 per cent to -3 per cent per annum. As Figure 5 shows, simulating a medium cycle generates quite different elasticity profiles. The medium cycle (with a profit growth range of 4.3 per cent to -0.2 per cent around a 2 per cent trend) produces elasticity profiles that are dramatically different from the benchmark case 
Comparing Groups/Single

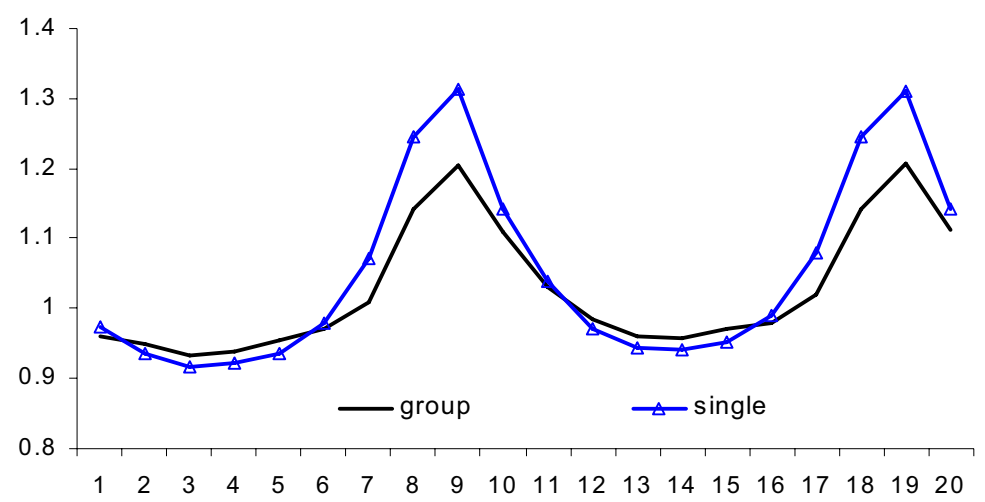

Figure 4: Elasticities: Benchmark case

(requiring a different scale for the vertical axis in Figure 5). Most noticeably, the tendency for the elasticity to rise during downturns is essentially reversed in Figure 5 with the elasticity dropping close to, or below, zero at the bottom of the recession, but with higher values going into and coming out of the recession.

This phenomenon is even more pronounced when a high cycle, with a range of 5.5 per cent to -1.4 per cent combined with a 2 per cent trend, is simulated. This produces elasticities as low as -4 at the bottom of the recession. This reflects the fact that more severe recessions produce many more firms and groups going into loss and hence becoming non-taxpayers, with zero revenue elasticities. Hence tax revenues can fall suddenly even if profit growth remains positive. Equally negative elasticities can arise when recessions generate negative profit growth but tax growth remains positive. This is the case for single firms in Figure 5 where the negative profit growth of -0.2 per cent in years 8 and 9 is insufficient to turn tax growth negative, with resulting negative elasticities. Small positive profit growth in year 10 (coming out of the recession) then yields a large positive elasticity. Figure 5 also suggests that, apart from during recessionary periods, the elasticity profile is relatively flat around a value of 1 .

These results suggest that a regular cyclical process, even without any 


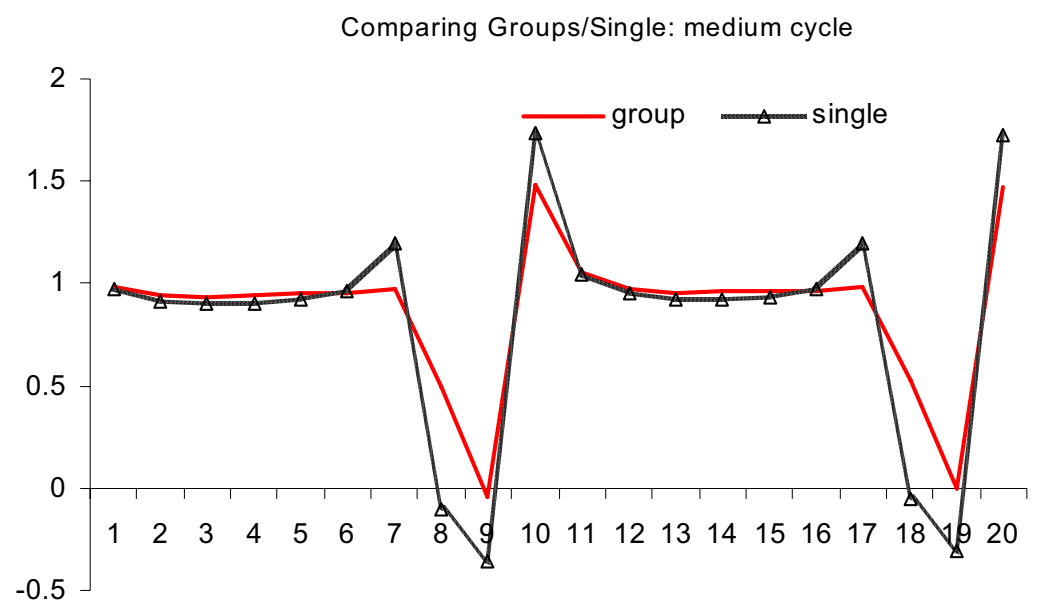

Figure 5: Elasticities: Medium cycle

stochastic effects, can nevertheless produce quite volatile revenue elasticities, moving quickly between positive and negative values in a similar manner to that observed for UK corporate tax buoyancy in Table 1.

\subsection{Introducing Relative Profit Changes}

In practice there are relative movements of firms within the profit distribution. Many firms can behave differently from the average, either because they make endogenous firm-specific changes with beneficial or adverse consequences for their profit levels, or because they experience unusual exogenous changes which affect their profits. The simulation model captures this by allowing for both random firm-specific profit shocks and the possibility of serial correlation in profits. In the latter case, a higher change in profits in one period may increase, or reduce, the probability of higher changes in profits in subsequent periods; this captures the phenomenon where 'success breeds success'.

To allow the extent to which random effects impact on firms' profits to vary, simulations were carried out using two alternative values for the variance terms, $\sigma_{u_{A}}^{2}, \sigma_{u_{B}}^{2}$ in equation (17) in Appendix B. Setting $\sigma_{u_{A}}^{2}=$ $\sigma_{u_{B}}^{2}=0.001$ is a relatively high variance, implying a standard deviation of 
around 3 per cent such that profit growth for about 50 per cent of firms lie outside \pm 3 per cent of the mean profit growth rate. That is, at the mid-point of a cycle with trend growth of 2 per cent, around half of all firms experience profit growth outside the -1 per cent to +5 per cent range. A lower variance of 0.0002 implies a \pm 1.4 per cent band around the mean, so half of all firms profit growth rates lie outside the range from +0.6 per cent to +3.4 per cent. Clearly, this still represents a fairly high degree of profit variability across firms.

To identify serial correlation within trading and loan-relationship profits, the CT600 data for 2001-02 to 2003-04 were analysed. This yielded serial correlation values around -0.25 for $A$ profits and -0.2 for $B$ profits. ${ }^{14}$ Simulations use values of $+0.2,0.0$ and -0.2 .

Figure 6 shows the impact on the revenue elasticity of allowing for the high and low variance cases above, with zero serial correlation. These are obtained for the group case with a medium cycle as shown in Figure 5. (The zero variance case in Figure 6 is equivalent to the group case in Figure 5; all simulations set serial correlation to zero). It can be seen in Figure 6 that allowing for stochastic effects further increases the volatility of the revenue elasticity especially, but not exclusively, during recessions (for example years $8-10)$. Finally allowing for positive or negative serial correlation $(-0.2,+0.2)$ in the random component of profit growth has little effect on the revenue elasticities. In both cases elasticity profiles look similar to those shown in Figure 6.

\subsection{Decomposing the Impact of Deductions}

It was shown above that the pro-cyclical nature of capital allowances (because investment is positively correlated with profits) and the counter-cyclical nature of firms' losses implies that these two deductions are expected simultaneously to have differing impacts on the aggregate corporation tax revenue elasticity. It is therefore useful to examine revenue elasticities obtained by setting each of these deductions, in turn, to zero. This effectively decomposes

\footnotetext{
${ }^{14}$ These values are obtained by assuming a first order auto-regressive process for the random component of $x_{i t}^{A}$ and $x_{i t}^{B}$; see Creedy and Gemmell (2006c).
} 


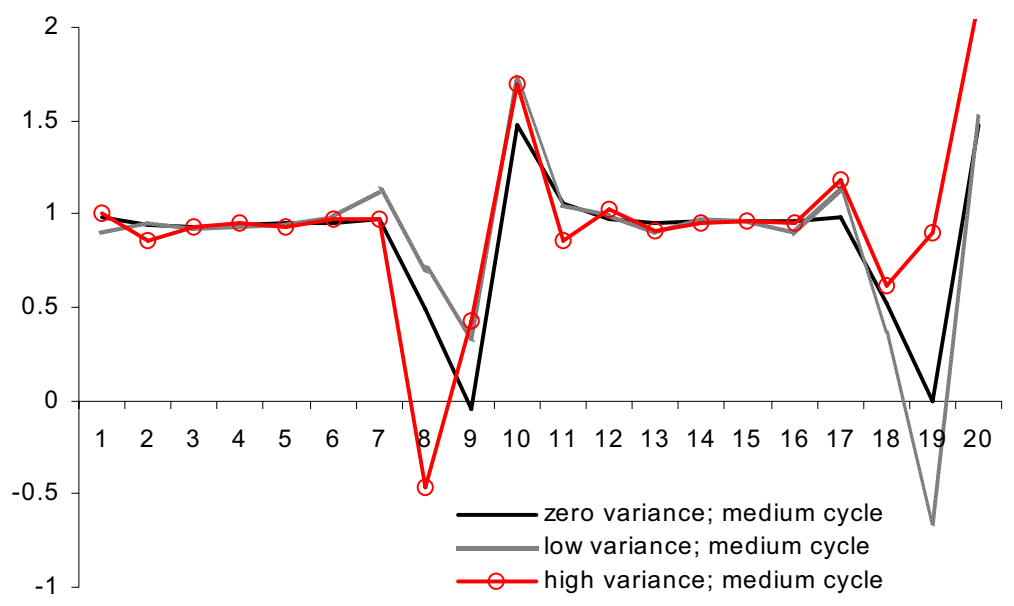

Figure 6: Elasticities: Introducing Stochastics

the elasticity into effects due to loss use and group relief growth, and effects due to capital allowance growth. Gross profit growth - the denominator of the elasticity - is the same in each case.

Figure 7 repeats the elasticity profile for medium-cycle parameter values, and also shows two decompositions: these are where there is no investment $(\alpha=\beta=0$ in $(7))$ and where there are no losses $\left(d^{A}=d^{B}=0\right)$. This confirms the expectation that, in the absence of any losses, the pro-cyclical assumption for capital allowances yields a smooth pro-cyclical elasticity profile. On the other hand, if only losses are used as deductions, the elasticity profile closely resembles the overall medium-cycle case. That is, the overall profile is most strongly driven by loss deductions rather than capital allowances. Clearly then, the relative importance of capital allowances and losses used within total deductions has a strong bearing on the cyclical nature of the revenue elasticity. Of course, in practice, investment is not linked to profits in the simple manner depicted here, with profit expectations, interest rates, lags and so on, likely to play a role. 


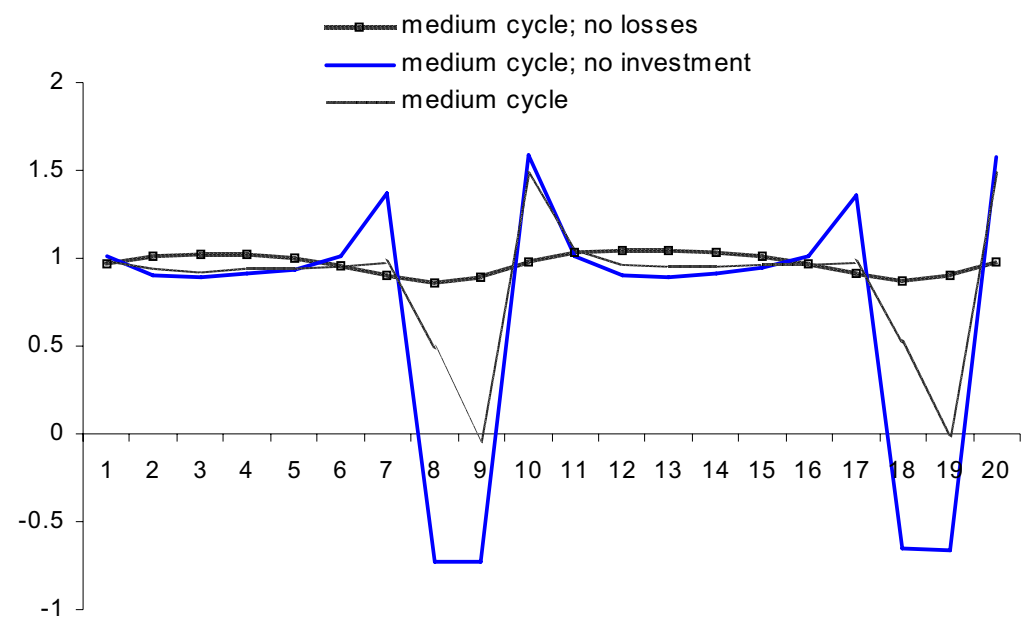

Figure 7: Elasticities: Decomposing Deductions

\subsection{Eliminating the Small Company Rate}

This subsection examines the revenue consequences of a change in the tax schedule: the details of the rates and thresholds that characterise the current corporate tax system are in Appendix A. However, the outcomes from such exercises should be treated as benchmark simulations of 'impact effects' since behavioural responses to tax changes are excluded. For example, simulating an increase in the main rate would identify the direct revenue effects of the increased tax rate. But it would not take into account potentially important reactions such as changes in reported gross profits in the UK, or firms' responses in the form of additional avoidance schemes to reduce tax liability for a given value of declared profits.

It was suggested above that large firms, paying the 30 per cent rate, account for the major share of receipts, and hence movements across the tax threshold from 19 per cent to 30 per cent would be unlikely to be important for revenue elasticity estimates. This can be tested by setting the tax rate in CorpSim to 30 per cent for all firms above the $£ 10 \mathrm{k}$ threshold. Results from this simulation confirm that the elasticity profile is little affected. For example, comparing results with the benchmark case, elasticities at the top 
of the cycle, where profit growth is 3.2 per cent, for the alternative tax rate scenarios are almost identical at 0.94 and 0.95. Differences are maximised at the bottom of the cycle where profit growth is 0.8 per cent. The benchmark elasticity is 1.20 whilst a value of 1.14 is obtained using a single 30 per cent tax rate for all firms. These differences in the revenue elasticity in the two scenarios arise from the increased revenues predicted when a single 30 per cent tax rate is adopted. Since any behavioural responses would be expected to reduce revenues below this impact effect, the limited responses to the tax change reported here can be regarded as maximum values.

\section{Revenue Elasticities over the Long-run}

The previous section demonstrated the volatility of the corporation tax revenue elasticity over the economic cycle, demonstrating that it can move substantially from year to year in response to changes in profit growth rates. This raises the question of whether, in a world of steady growth, an elasticity value of 1 can be presumed. That is, given the UK corporation tax system, can taxes and profits be expected to grow at the same rate in a steady state? Alternatively, given the existence of economic cycles, and therefore volatile annual revenue elasticities, can the revenue elasticity be expected to average 1 over a complete cycle?

Table 7: Elasticities over the Long-run

\begin{tabular}{llcc}
\hline Simulation & & $\begin{array}{c}\text { Long-run } \\
\text { elasticity }\end{array}$ & $\begin{array}{c}\text { Average } \\
\text { elasticity }\end{array}$ \\
\hline Benchmark & & 0.99 & 1.02 \\
Medium cycle & & 0.98 & 0.86 \\
High cycle & & 0.98 & 0.15 \\
Low variance & (Low cycle) & 0.97 & 1.02 \\
High variance & (Low cycle) & 1.00 & 1.03 \\
Low variance & (Medium cycle) & 0.99 & 0.95 \\
High variance & (Medium cycle) & 1.00 & 0.83 \\
\hline
\end{tabular}

Table 7 shows values for the long-run revenue elasticity, estimated from revenue and gross profit growth over 10 periods $\left(t_{1}\right.$ to $\left.t_{10}\right)$ - a complete cycle 
in the model. It also shows an average revenue elasticity: this is the arithmetic average of the 10 annual values of the elasticity, over the same period. The benchmark case shows that, with low volatility in growth rates (both profits and tax), but no stochastic behaviour, both the elasticity measures approximate 1 (they are 0.99 and 1.02). More volatile behaviour, whether due to greater cyclical effects or stochastic effects, continues to be associated with a long-run elasticity close to 1 but the additional volatility renders the average elasticity value a very poor proxy for the long-run value. Especially with a high cycle, the single large negative annual value, at the bottom of the cycle, dominates the 10-year average.

These results suggest that, despite variability across firms in their profit growth being the norm in practice, over a complete cycle, profit and tax growth are approximately equal. However, given the observed volatility in profit growth rates over time, using averages of annual elasticity values is likely to be misleading.

The simulation model incorporates thousands of firms, each with potentially very different gross profit growth rates such that some firms have zero tax revenue elasticities (non-taxpayers) while others can take a range of positive values greater than 1 . Given this, it may seem surprising that the model robustly predicts a long-run revenue elasticity, averaged across all firms, that is so close to 1 . However, this result can be explained by recalling that, for unchanged tax rates, tax revenue growth is equal to the growth of net profits (that is, net of all deductions). An elasticity of 1 implies that gross and net profits must be growing at the same rate over the long-run. A sufficient condition for this to occur is that deductions and gross profits grow at the same rate, over the long-run. ${ }^{15}$

This last condition is what might be expected over a complete cycle, and is implicit in the simulation model's assumptions. Over a complete cycle (and especially over several cycles) it would be surprising if investment, and hence capital allowances, were persistently increasing or decreasing relative

\footnotetext{
${ }^{15}$ Since net profit, $P^{T}=P-D$, then, using a 'dot' over a variable to represent its rate of growth, $\dot{P}^{T}=\alpha \dot{P}-(1-\alpha) \dot{D}$, where $\alpha=P / P^{T}>1$. If $\dot{P}$ and $\dot{D}$ are equal, they both equal $\dot{P}^{T}$ independently of the value of $\alpha$.
} 
to profits, though such a pattern might extend for some time. For losses, the other major contributor to deductions, there is no reason to expect those to increase or decrease relative to positive profits over the long-run. For example, though losses are expected to worsen relative to profits during a temporary downturn, if they became larger in successive cyclical downturns, it would imply a long-run worsening of profitability in the economy. Such a phenomenon is not typically observed over several cycles.

\section{Conclusions}

This paper has addressed the question of how corporation tax receipts are expected to grow over time, given an unchanged corporation tax regime and compliance effort. Despite the existence of a number of forecasting methods to predict corporation tax revenues (receipts or accruals) this question has previously received surprisingly little attention. This is important for two reasons. First, with growing public expenditure demands, it is necessary for tax authorities to know whether, in the absence of budgetary changes, they can expect improving or worsening revenues from corporation tax both over the longer-term and within an economic cycle. Second, if corporation tax revenues can rise or fall without any changes in compliance, but revenue targets are used to assess compliance effort, the ability to meet these will be influenced by factors inherent to the corporation tax system but outside the control of compliance units.

Simulation results suggest a number of conclusions. The growth of aggregate corporation tax revenue appears to be highly volatile in relation to the growth of profits. Volatility in revenue elasticities is generally less when groups can share losses compared with an economy composed only of single firms. Relatively high volatility in revenue elasticities is especially associated with economic downturns (otherwise elasticities tend to hover around a value of 1). This volatility occurs even when all firms' profits are assumed to grow at the same rate, but is exacerbated when random factors allow some firms to deviate from this common growth rate. In mild economic downturns, corporation tax revenue elasticities may rise (because tax growth falls less than 
profit growth), but in more severe downturns, large but temporary decreases in the revenue elasticity (and even negative elasticities) can be expected.

Capital allowances and losses claimed against positive profits have quite different effects on revenue elasticities, if in general capital allowances are positively correlated (and losses negatively correlated) with profits. Over a full economic cycle, the model predicts plausibly that corporation tax revenues and profits tend to grow at the same rate (in the absense of discretionary changes in tax rates, compliance and so on). However, due to the short-run volatility, annual averages of revenue elasticities are a misleading guide to long-run tax growth.

The empirical analysis of Devereux et al. (2004) sought to explain why UK corporation tax revenues had, in general, remained high relative to GDP since the mid-1980s, despite falling statutory corporation tax rates. They concluded that the main factor behind this was the expansion in the share of corporate profits in GDP, mainly associated with financial companies. This therefore expanded the tax base, relative to GDP. The simulation model described here has focused on how revenues change relative to the tax base, suggesting that these are expected to be stable over the long-run, but quite unstable in the short-run. How the tax base, profits, might change over time requires a separate analysis recognising behavioural factors, including the potential for the tax regime itself to influence firms' profitability and how and where their profits are declared for tax purposes.

Although many simplifications were required in constructing and calibrating the microsimulation model CorpSim, it is able to capture many of the crucial features of the distribution of profits in the UK and their relative movements. The simulation results have demonstrated the value of producing a model of this kind, in view of its ability to generate valuable insights into the behaviour of corporation tax revenue elasticities. 


\section{Appendix A: The UK Corporate Tax Schedule}

This appendix describes the actual UK corporation tax schedule, the relationship between the corporation tax paid, $T$, and net (taxable) profit, $P^{T}$, so that $T=T\left(P^{T}\right)$. The tax schedule in the UK involves four net profit thresholds, $m_{0}, \ldots, m_{4}$, two tax rates $t_{1}$ and $t_{2}$, and two 'marginal relief fractions', $F_{1}$ and $F_{2}$. The tax within each range is given in Table 8 .

Table 8: The Corporate Tax Schedule

\begin{tabular}{ll}
\hline Profit Range & Tax \\
\hline$P^{T} \leqslant m_{0}$ & $T\left(P^{T}\right)=0$ \\
$m_{0}<P^{T} \leqslant m_{1}$ & $T\left(P^{T}\right)=t_{1} P^{T}-F_{1}\left(m_{1}-P^{T}\right)$ \\
$m_{1}<P^{T} \leqslant m_{2}$ & $T\left(P^{T}\right)=t_{1} P^{T}$ \\
$m_{2}<P^{T} \leqslant m_{3}$ & $T\left(P^{T}\right)=t_{2} P^{T}-F_{2}\left(m_{3}-P^{T}\right)$ \\
$P^{T}>m_{3}$ & $T\left(P^{T}\right)=t_{2} P^{T}$ \\
\hline
\end{tabular}

There are therefore two ranges of net profit, $m_{1}<P^{T} \leqslant m_{2}$ and $P^{T}>m_{3}$ where taxation is a fixed proportion of net profit, $t_{1}$ and $t_{2}$ respectively. Average and marginal tax rates are conventionally defined with respect to the gross tax base, in this case gross profits, $P$. Hence

$$
A T R=\frac{T\left(P^{T}\right)}{P}=\frac{T\left(P^{T}\right)}{P^{T}} \frac{P^{T}}{P}
$$

and:

$$
M T R=\frac{d T}{d P}=\frac{d T}{d P^{T}} \frac{d P^{T}}{d P}
$$

However, since the corporation tax schedule specifies the relationship between the corporation tax paid, $T$, and net profit, $P^{T}$, average and marginal tax ratios may be defined as:

$$
\operatorname{ATR}\left(P^{T}\right)=\frac{T\left(P^{T}\right)}{P^{T}}
$$

and:

$$
\operatorname{MTR}\left(P^{T}\right)=\frac{d T}{d P^{T}}
$$

Hence within each net profit range in Table 8, the average and marginal tax ratios are as shown in Table 9. These are illustrated in Figure ??. 
Table 9: Average and Marginal Tax Ratios

\begin{tabular}{lll}
\hline Profit Range & \multicolumn{1}{c}{$A T R\left(P^{T}\right)$} & $M T R\left(P^{T}\right)$ \\
\hline$P^{T} \leqslant m_{0}$ & 0 & 0 \\
$m_{0}<P^{T} \leqslant m_{1}$ & $t_{1}-F_{1}\left(\frac{m_{1}}{P^{T}}-1\right)$ & $t_{1}+F_{1}$ \\
$m_{1}<P^{T} \leqslant m_{2}$ & $t_{1}$ & $t_{1}$ \\
$m_{2}<P^{T} \leqslant m_{3}$ & $t_{2}-F_{2}\left(\frac{m_{2}}{P^{T}}-1\right)$ & $t_{2}+F_{2}$ \\
$P^{T}>m_{3}$ & $t_{2}$ & $t_{2}$ \\
\hline
\end{tabular}

For example, over the range $m_{0} \leqslant P^{T} \leqslant m_{1}$ the ratio, $T\left(P^{T}\right) / P^{T}$, gradually increases from 0 to $t_{1}$, such that:

$$
\frac{T\left(P^{T}\right)}{P^{T}}=t_{1}-F_{1}\left(\frac{m_{1}}{P^{T}}-1\right)
$$

and $t_{1}$ is reduced by a fraction of the proportional difference between $m_{1}$ and net profit. The tax schedule obviously differs from a typical income tax schedule where, for example, a higher tax rate is applied only to income measured above the relevant threshold, and lower ranges of income are taxed at lower rates. For a firm with $P^{T}$ in excess of $m_{3}$, all of net taxable profit is subject to the higher rate of $t_{2}$.

The two marginal relief fractions are determined in order to ensure that there are no discontinuities in the tax schedule. ${ }^{16}$ These properties mean that although $T\left(P^{T}\right) / P^{T}$ is either constant or increasing, the tax schedule as a whole does not display marginal tax rate progression. Over the range $m_{0}<P^{T} \leqslant m_{1}$ the term $d T / d P^{T}=t_{1}+F_{1}$, and this falls to $t_{1}$ over the range $m_{1}<P^{T} \leqslant m_{2}$. Similarly, $d T / d P^{T}$ falls from $t_{2}+F_{2}$ over the range $m_{2}<P^{T} \leqslant m_{3}$, to $t_{2}$ when $P^{T}>m_{3}$.

The parameters of the current schedule are given in Table 10. These values apply to single firms where no group relief is relevant. In the group case, the profit thresholds, $m_{0}$ to $m_{4}$, are divided by the number of firms in the group, and the marginal relief fractions adjusted accordingly.

\footnotetext{
${ }^{16}$ For example, $T\left(P^{T}=m_{0}\right)=0=t_{1} m_{0}-F_{1}\left(m_{1}-m_{0}\right)$, so that $F_{1}=\frac{t_{1} m_{0}}{m_{1}-m_{0}}$. Similarly, $T\left(P^{T}=m_{2}\right)=t_{1} m_{2}=t_{2} m_{2}-F_{2}\left(m_{3}-m_{2}\right)$, and thus $F_{2}=\frac{m_{2}\left(t_{2}-t_{1}\right)}{m_{3}-m_{2}}$.
} 
Table 10: Parameters of Tax Schedule: 2006

\begin{tabular}{ll}
\hline Parameter & Value \\
\hline$m_{0}$ & $10 k$ \\
$m_{1}$ & $50 k$ \\
$m_{2}$ & $300 k$ \\
$m_{3}$ & $1500 k$ \\
$t_{1}$ & 0.19 \\
$t_{2}$ & 0.30 \\
$F_{1}$ & $19 / 400$ \\
$F_{2}$ & $11 / 400$ \\
\hline
\end{tabular}

\section{Appendix B: Modelling Profit Dynamics}

This appendix describes the profit generating component of CorpSim and gives the parameter values used in the simulations reported above. The first section describes the specification of the initial joint distribution of profits from the two sources. ${ }^{17}$ The procedure used to simulate changes is then described. The final section gives parameter values used. ${ }^{18}$

\section{Profits in the Initial Period}

The distribution of profits is positively skewed, with a substantial left-hand tail in the region of negative profits. The distribution is highly peaked, as well as containing long flat tails. For this reason, a functional form such as the lognormal distribution, which is widely used in analyses of incomes, is unable to capture the shape of the distribution of $P^{A}+d \cdot{ }^{19}$ The approach taken here is thus to use a mixture distribution. A proportion $\alpha_{1}$ of the density of $P^{A}+d$ is modelled using a lognormal distribution $\Lambda\left(\mu_{1}, \sigma_{1}^{2}\right)$, in

\footnotetext{
${ }^{17}$ An alternative approach could use micro-data on company profits to generate the crosssectional data on which the initial joint A and B distribution could be based. However, the present method makes it possible to examine the effects of changes in the distribution.

${ }^{18}$ For a more extensive analysis of UK profits data and the profit model, see Creedy and Gemmell (2006b).

${ }^{19}$ The lognormal is defined only for positive values, so that $P^{A}+d$ is the relevant variable, rather than $P^{A}$.
} 
which $\sigma_{1}^{2}$ is relatively large to capture a platykurtic feature. ${ }^{20}$ To capture the leptokurtic, or peaked, feature, a proportion $\alpha_{2}$ is modelled using a lognormal distribution $\Lambda\left(\mu_{2}, \sigma_{2}^{2}\right)$ in which $\sigma_{2}^{2}$ is relatively small. However, this type of mixture does not capture the long right hand tail of the distribution. Hence a third component distribution is used, consisting of the upper tail (values of $P^{A}+d$ above the threshold, $\xi$, of another lognormal distribution, $\left.\Lambda\left(\mu_{3}, \sigma_{3}^{2}\right)\right)$. The importance of this third distribution lies in the fact that the upper tail of the profit distribution is responsible for the bulk of corporation tax payments. For example, when companies are ranked by the size of their corporation tax liabilities in 2003-04, HMRC data show that the largest 8 per cent of all corporation tax payers accounted for almost 90 per cent of all companies' corporation tax liabilities.

With two income sources, $P^{A}$ and $P^{B}$, there are corresponding values of $x_{A}=P^{A}+d^{A}$ and $x_{B}=P^{B}+d^{B}$. Hence, it is necessary to consider the joint distribution of the initial values of $x_{A}$ and $x_{B}$. In generating the distribution of source $B$ profits, the upper tail component is not used and, instead, additional density is added to the peaked distribution. This is because the histograms of loan relationship profits do not display such a long upper tail, but are even more peaked than those of source $A$ profits.

\section{Simulating Profit Changes}

The following sequence is used to generate the changing distribution of profits. First, the random component of proportional changes for the $A$ source is given, where $v_{u, i}^{A}$ is a random draw from an $N(0,1)$ distribution, by:

$$
u_{i, t}^{A}=\gamma u_{i, t-1}^{A}+\sigma_{u_{A}} v_{u, i}^{A}
$$

To allow for the possibility that stochastic shocks to $A$ and $B$ may be correlated, assume that $u^{A}$ and $u^{B}$ are jointly Normally distributed as

$$
N\left(u^{A}, u^{B} \mid 0,0, \sigma_{u_{A}}, \sigma_{u_{B}}, \rho\right) .
$$

\footnotetext{
${ }^{20}$ This has relatively low kurtosis and thus captures the more central portion of the distribution.
} 
A value of $u^{B}$ is then given by:

$$
u_{i, t}^{B}=\rho\left(\frac{\sigma_{u_{A}}}{\sigma_{u_{B}}}\right) u_{i, t}^{A}+\left\{\sigma_{u_{B}} \sqrt{1-\rho^{2}}\right\} v_{u, i}^{B}
$$

Thus, the two profit sources are generated using:

$$
P_{i, t}^{A}=P_{i, t-1}^{A}\left(1+g_{t}^{A}+u_{i, t}^{A}\right)-\left(d_{t}^{A}-d_{t-1}^{A}\right)+d_{t-1}^{A}\left(g_{t}^{A}+u_{i, t}^{A}\right)
$$

and:

$$
P_{i, t}^{B}=P_{i, t-1}^{B}\left(1+g_{t}^{B}+u_{i, t}^{B}\right)-\left(d_{t}^{B}-d_{t-1}^{B}\right)+d_{t-1}^{B}\left(g_{t}^{B}+u_{i, t}^{B}\right)
$$

With two income sources, $P^{A}$ and $P^{B}$, there are corresponding values of $x_{A}=P^{A}+d^{A}$ and $x_{B}=P^{B}+d^{B}$. Hence, it is necessary to consider the joint distribution of the initial values of $x_{A}$ and $x_{B}$. The approach adopted here is to obtain random draws from the appropriate distribution of $x_{A}$, and then to select random draws from the conditional distribution of $x_{B}$, given $x_{A}$. For each of the components of the mixture distribution described in the previous subsection, suppose that they are jointly lognormally distributed as:

$$
\Lambda\left(x_{A}, x_{B} \mid \mu_{A}, \mu_{B}, \sigma_{A}^{2}, \sigma_{B}^{2}, \rho\right)
$$

Consider the $i$ th firm. If $v_{i}^{A}$ is a random draw from an $N(0,1)$ distribution, an initial value of $x_{A}$, obtained from the marginal distribution of $x_{A}$, is given by:

$$
\log \left(x_{A, i}\right)=\mu_{A}+\sigma_{A} v_{i}^{A}
$$

If $v_{i}^{B}$ is another random draw from an $N(0,1)$ distribution, an initial value of $x_{B}$ is obtained from the conditional distribution of $x_{B}$, given $x_{A}$. Using the fact that $\log \left(x_{B} \mid x_{A}\right)$ is normally distributed with mean $\mu_{B}+\rho\left(\frac{\sigma_{A}}{\sigma_{B}}\right)\left(x_{A}-\mu_{A}\right)$ and variance $\sigma_{B}^{2}\left(1-\rho^{2}\right)$, a simulated value of $x_{B, i}$ is given by:

$$
\log \left(x_{B, i}\right)=\mu_{B}+\rho\left(\frac{\sigma_{A}}{\sigma_{B}}\right)\left(x_{A, i}-\mu_{A}\right)+\left\{\sigma_{B} \sqrt{1-\rho^{2}}\right\} v_{i}^{B}
$$

Hence $P_{i}^{A}=x_{A, i}-d^{A}$ and $P_{i}^{B}=x_{B, i}-d^{B}$. In the case of the component capturing the long upper tail of the distribution, all random draws from $x_{A}$ which are less than $\xi$ are rejected. For $x_{A}>\xi$, the corresponding conditional value of $x_{B}$ is obtained, without the constraint being imposed. In each component of the mixture, the correlation coefficient, $\rho$, is assumed to be the same. 


\section{Calibrating the Model: Profits}

Table 11 shows parameter values for the profit distributions and the characteristics of changes in the distribution over time. The objective is to capture its essential characteristics so that the simulated distribution approximates, for example, the extent of losses and the distribution of profit levels relative to tax thresholds.

Specifying $d^{A}$ and $d^{B}$ using the minimum values observed in the CT600 dataset is not appropriate, since these are extremely large values - in the hundred millions or billions. Experimentation suggested that setting $d^{A}=$ $d^{B}=£ 600 \mathrm{k}$, together with the means and variances shown in Table 11, yielded reasonably close approximations for the $P^{A}$ and $P^{B}$ distributions. For example, the resulting distribution of $P^{A}$ (trading profits) is shown in Figure 8. This is compared with the actual distribution of trading profits, $P^{A}$, for the latest year available (2003-04). This is based on data for around 160k firms in HMRC's CT600 database: the Figure shows a representative sample of $15 \mathrm{k}$ firms. ${ }^{21}$ Data on trading profits and losses (Gross Case 1 profits and losses) have been combined to produce the distribution shown. The simulated distribution captures the peakedness of the distribution fairly well, but with numbers in the larger loss classes slightly over-predicted. A similar distribution was obtained for loan-relationship profits, $P^{B}$, (Gross Case 3 income and losses). This is similar to that shown in Figure 8 but is even more concentrated around $-£ 50 \mathrm{k}$ to $+£ 50 \mathrm{k}$, with a mode in the $-£ 50 \mathrm{k}$ to $£ 0$ class.

As Table 11 shows, the initial distribution is modelled using platykurtic and leptokurtic lognormal distributions, for both $A$ and $B$, with the same means (6.425), but with the former having a larger variance ( 0.35 versus 0.05 for $A ; 0.001$ versus 0.0001 for $B$ ). For profit source $A$, the third distribution, contributing only to the 10 per cent of firms in the upper tail, has a much higher mean and variance (8.5 and 1.8 respectively). Furthermore, values

\footnotetext{
${ }^{21}$ Companies for which this database recorded zero profits and zero turnover were omitted. The CT600 data are derived from companies' replies on their CT600 form, prior to any assessment/analysis by HMRC. It may therefore include errors that subsequent enquiries correct.
} 
Table 11: Parameters of the Profit Distributions

\begin{tabular}{ll}
\hline Parameter value & Description \\
\hline & Initial Profit Distribution \\
6.4250 .35 & Mean and variance of $\log ($ profit $+\mathrm{d}): \mathrm{A}$ \\
6.4250 .05 & Mean and variance of $\log ($ profit $+\mathrm{d}): \mathrm{B}$ \\
$600 \mathrm{k}$ & Maximum -ve profit: A and B \\
0.05 & Correlation between profit sources \\
0.45 & Proportion peaked component \\
6.4250 .001 & Mean and variance of $\log ($ profit $+\mathrm{d}):$ peaked A \\
6.4250 .0001 & Mean and variance of $\log ($ profit $+\mathrm{d}):$ peaked B \\
0.10 & Proportion in upper tail: A \\
8.51 .8 & Mean and variance of $\log ($ profit $+\mathrm{d}):$ A upper tail \\
$1500 \mathrm{k}$ & Profit threshold for upper tail: A \\
\hline & Dynamic components \\
0.000001 & Variance of random component: A and B \\
0 & Serial correlation coefficient (random changes) \\
\hline
\end{tabular}

of $x_{i}<1500 \mathrm{k}$ generated from this distribution component are ignored. The table also shows a correlation between $A$ and $B$ profits of $\rho=0.05$; see equation (20). This is the value used in benchmark simulations in section 6 where a number of alternatives are examined based on analysis of CT600 data for 2003-04. 


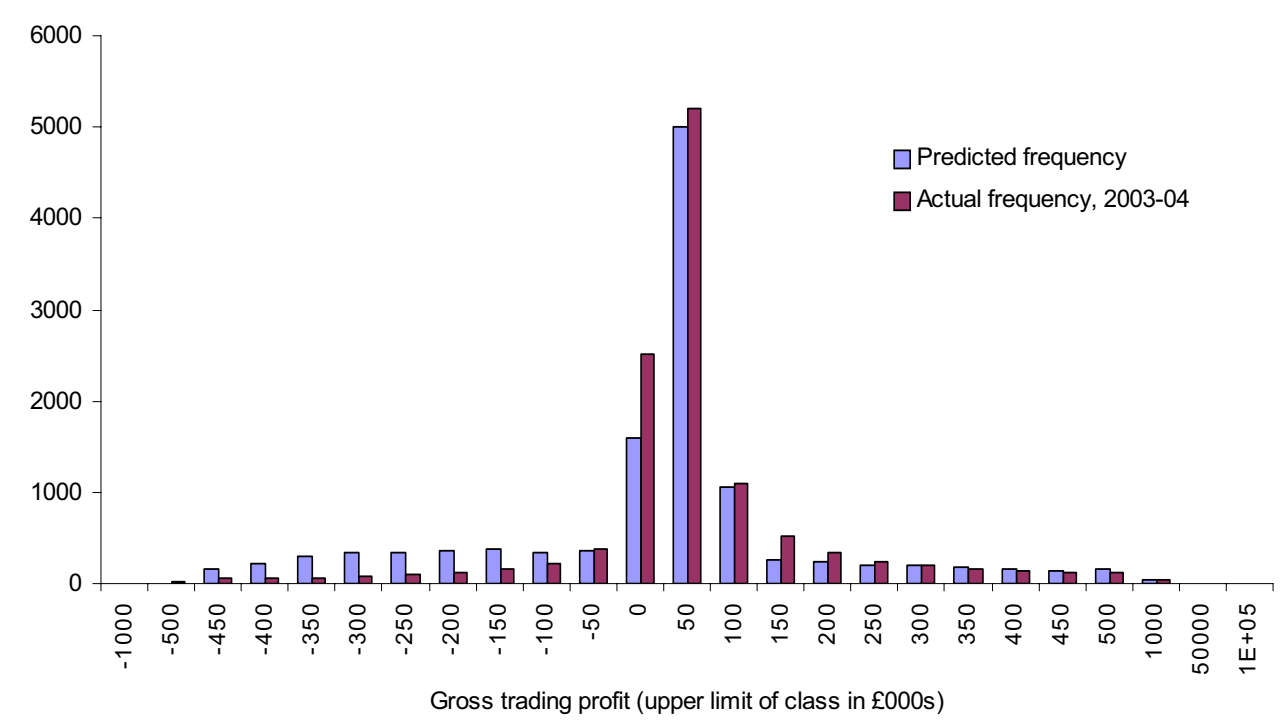

Figure 8: Actual and Simulated Trading Profits, 2003-04

\section{Appendix C: Modelling Alternative Deductions Claiming by Groups}

This appendix compares results using the tax minimising assumption with an alternative assumption that groups adopt a fixed order in which available deductions are claimed. In particular, deductions are subtracted in the following order: (i) capital allowances; (ii) current losses are deducted within firms; (iii) excess capital allowances are deducted within firms; (iv) losses are group relieved; (v) losses are brought forward from previous periods and claimed within firms. This order essentially reflects a rule of thumb that current deductions are used within a firm first and are made available to group members only if they cannot be fully used. As with other simulations, past losses are treated as the final deduction to be used because, unlike other deductions, their use is already constrained to be within firms and within schedule.

Figure 9 shows the revenue elasticity schedules using the medium cycle and low variance of the random growth component, for both the tax min- 


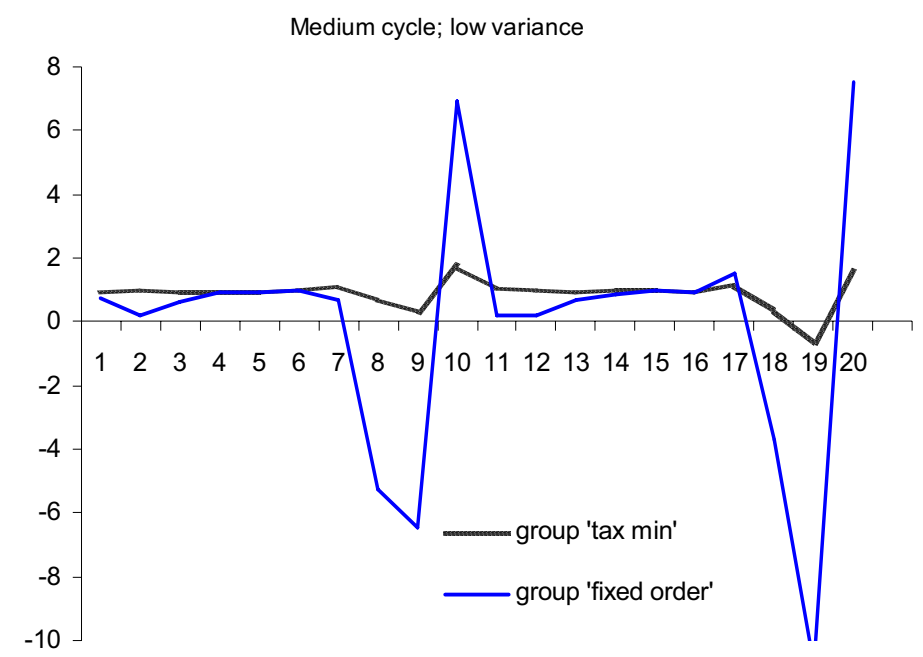

Figure 9: Elasticities: Comparing Deduction Methods

imising and fixed order cases. It is clear that the method adopted can be important for the measured size of the elasticity. It is more volatile in the fixed order case, especially during recessions, when the fixed order case can reach values of -10 .

It is easier to assess what lies behind this result by considering Figure 10, which shows profiles for aggregate tax revenues over the 20 year simulation, for the two cases. This indicates, as expected, that the tax minimising profile always lies below the alternative (non-minimising) case. However, it is especially during recessions that tax minimisation makes a strong contribution by allocating losses most efficiently for the group. As Figures 9 and 10 show, failing to do this makes a substantial difference to the levels of tax liability and the elasticity estimates in periods of large losses. 


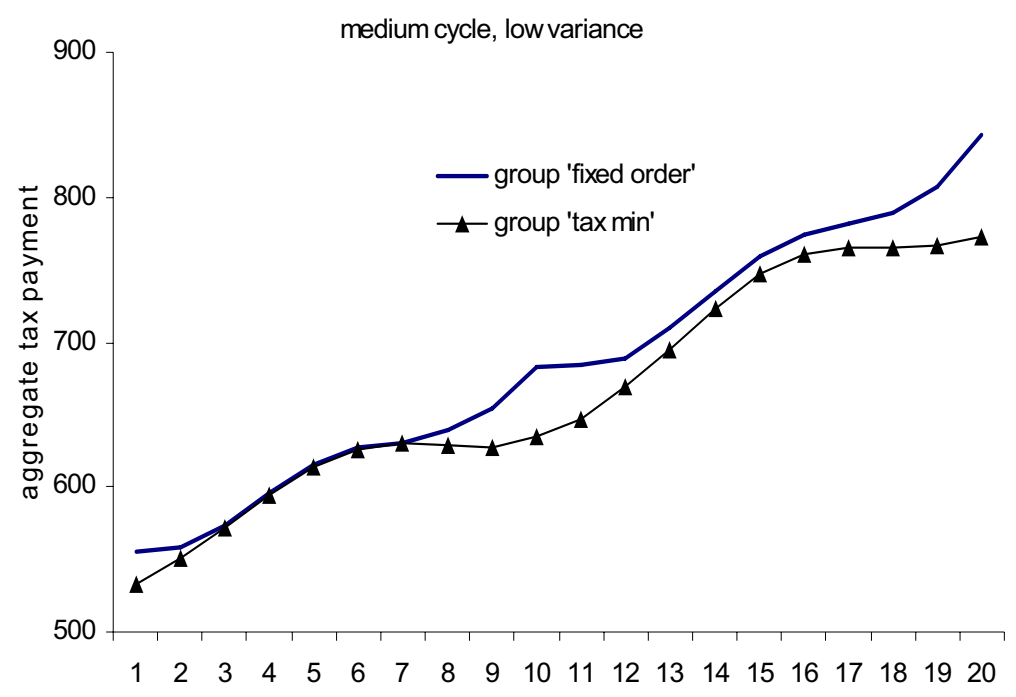

Figure 10: Alternative Tax Revenue Profiles

\section{Appendix D: Group Loss-sharing Examples}

This appendix illustrates how the algorithm to minimise group net profits and stranded losses is applied to the various gross profit and loss combinations which can arise within groups of two firms, labelled $i$ and $j$. Of the ten possible combinations discussed in the text, there are eight cases where sharing of losses is an option. The other cases are where profits from all sources are positive, or all are negative.

Tables 12 to 15 show three examples each for the eight combinations of interest. To focus on the use of losses, capital allowances are set to zero in all cases. These examples represent three alternative configurations of current losses and loss pools to be carried forward and used as profit off-sets. These examples are:

i. Losses arising within the group in period $t$ are greater than the sum of positive profits (net of capital allowances) within the group in period $t$. In this case the maximum possible available losses are used to off-set positive profits, and there is no use in period $t$ of loss pools brought forward from period $t-1$. Unused losses arising in period $t$ are added 
to the relevant loss pools carried forward to period $t+1$.

ii. Losses arising within the group in period $t$ are less than the sum of positive profits (net of capital allowances) within the group in period $t$, and these profits net of current losses exceed the sum of the available loss pools from period $t-1$. In this case, all available current losses are used to off-set positive profits in period $t$, and all loss pools brought forward from period $t-1$ can also be used in period $t$.

iii. Losses arising within the group in period $t$ are less than the sum of positive profits (net of capital allowances) within the group in period $t$, but profits net of current losses are less than the sum of the available loss pools from period $t-1$. In this case, all available current losses are used to off-set positive profits in period $t$, and only a fraction of the available loss pools brought forward from period $t-1$ can be used in period $t$.

Example (iii) therefore requires a search procedure to identify the optimal allocation of current losses and losses brought forward. The optimum in this case is that combination which both minimises group net profits (and hence tax, for a given tax rate), and the carry forward of losses to period $t+1$, where they could become stranded in future. In Tables 12 to 15 the terms $\theta_{1}$ and $\theta_{2}$ indicate the resulting proportions of losses used as group relief to off-set $A$ and $B$ profits respectively (from firm $i$ to firm $j$ or vice varsa). ${ }^{22}$ The remaing proportion, $1-\theta_{1}-\theta_{2}$, is used within the loss-making firm (if $\left.\theta_{1}+\theta_{2}<1\right)$. Having searched across all possible combinations, there may be several values of $\theta_{1}$ and $\theta_{2}$ which achieve the optimum outcome. In this case, the simulation model chooses the first one identified.

\section{Further Details of Case 2}

To illustrate how the model allocates losses, the three examples shown for Case 2 in Table 12 are described in more detail here. Table 16 shows example

\footnotetext{
${ }^{22}$ Tables 12 to 15 also record the number of cases examined in order to identify the optimal values of $\theta_{1}$ and $\theta_{2}$.
} 
Table 12: Use of Losses: Cases 2 and 3

\begin{tabular}{lrrrrrr}
\hline \multicolumn{1}{c}{ Example: } & case 2 & & & case 3 & \\
Firm $i$ & $(\mathrm{ii})$ & $(\mathrm{iii})$ & $(\mathrm{i})$ & $(\mathrm{ii})$ & $(\mathrm{iii})$ \\
Profit A: & & & & & & \\
Profit B: & 400 & 400 & 1000 & 400 & 400 & 1000 \\
Initial LP A & 500 & 200 & 500 & 200 & 200 & 500 \\
Initial LP B & 100 & 100 & 200 & 100 & 100 & 200 \\
net profit A: & 0 & 100 & 0 & 0 & 0 & 0 \\
net profit B: & 0 & 0 & 0 & 0 & 100 & 0 \\
loss claimed A: & 0 & 0 & 0 & 0 & 0 & 0 \\
loss claimed B: & 0 & 0 & 0 & 0 & 0 & 0 \\
loss pool A: & 500 & 0 & 4200 & 500 & 0 & 4200 \\
loss pool B: & 100 & 0 & 200 & 100 & 0 & 200 \\
& & & & & & \\
Firm $j$ & & & & & & \\
Profit A: & 100 & 100 & 100 & -800 & -400 & -800 \\
Profit B: & -800 & -400 & -800 & 100 & 100 & 100 \\
Initial LP A & 50 & 50 & 100 & 50 & 100 & 100 \\
Initial LP B & 50 & 100 & 100 & 50 & 50 & 100 \\
net profit A: & 0 & 0 & 0 & 0 & 0 & 0 \\
net profit B: & 0 & 0 & 0 & 0 & 0 & 0 \\
loss claimed A: & 0 & 0 & 0 & 700 & 400 & 800 \\
loss claimed B: & 700 & 400 & 800 & 0 & 0 & 0 \\
loss pool A: & 50 & 0 & 100 & 150 & 100 & 100 \\
loss pool B: & 150 & 100 & 100 & 50 & 0 & 100 \\
& & & & & & \\
$\theta_{1}$ : & 0 & 0 & 0.25 & 0 & 0 & 0.25 \\
$\theta_{2}$ : & 0 & 0 & 0.625 & 0 & 0 & 0.625 \\
Cases exmined: & 0 & 0 & 147 & 0 & 0 & 147 \\
\hline & & & & & &
\end{tabular}


Table 13: Use of Losses: Cases 4 and 6

\begin{tabular}{|c|c|c|c|c|c|c|}
\hline & & case 4 & & & ase 6 & \\
\hline Example: & (i) & (ii) & (iii) & (i) & (ii) & (iii) \\
\hline Firm $i$ & & & & & & \\
\hline Profit A: & 200 & 1000 & 1000 & 200 & 1200 & 1200 \\
\hline Profit B: & 300 & 300 & 300 & -300 & -300 & -300 \\
\hline Initial LP A & 100 & 100 & 1000 & 100 & 100 & 1000 \\
\hline Initial LP B & 200 & 200 & 200 & 200 & 200 & 200 \\
\hline net profit $A$ : & 0 & 100 & 0 & 0 & 600 & 0 \\
\hline net profit B: & 0 & 0 & 0 & 0 & 0 & 0 \\
\hline loss claimed A: & 0 & 0 & 0 & 0 & 0 & 0 \\
\hline loss claimed B: & 0 & 0 & 0 & 200 & 300 & 300 \\
\hline loss pool A: & 100 & 0 & 607.5 & 100 & 0 & 300 \\
\hline loss pool B: & 200 & 0 & 192.5 & 300 & 200 & 200 \\
\hline Firm $j$ & & & & & & \\
\hline Profit A: & -600 & -600 & -600 & 400 & 400 & 400 \\
\hline Profit B: & -300 & -300 & -300 & -500 & -500 & -500 \\
\hline Initial LP A & 100 & 100 & 100 & 100 & 100 & 100 \\
\hline Initial LP B & 200 & 200 & 200 & 200 & 200 & 200 \\
\hline net profit $A$ : & 0 & 0 & 0 & 0 & 0 & 0 \\
\hline net profit B: & 0 & 0 & 0 & 0 & 0 & 0 \\
\hline loss claimed A: & 200 & 600 & 600 & 0 & 0 & 0 \\
\hline loss claimed B: & 300 & 300 & 300 & 400 & 500 & 500 \\
\hline loss pool A: & 500 & 100 & 100 & 100 & 0 & 0 \\
\hline loss pool B: & 200 & 200 & 200 & 300 & 200 & 200 \\
\hline$\theta_{1}:$ & 0 & 0 & 0.675 & 0 & 0 & 0.375 \\
\hline$\theta_{2}:$ & 0 & 0 & 0 & 0 & 0 & 0 \\
\hline Cases exmined: & 0 & 0 & 14 & 0 & 0 & 21 \\
\hline
\end{tabular}


Table 14: Use of Losses: Cases 8 and 10

\begin{tabular}{|c|c|c|c|c|c|c|}
\hline & & case 8 & & & ise 10 & \\
\hline Example: & (i) & (ii) & (iii) & (i) & (ii) & (iii) \\
\hline Firm $i$ & & & & & & \\
\hline Profit A: & 200 & 1200 & 1200 & -300 & -300 & -300 \\
\hline Profit B: & -300 & -50 & -50 & 300 & 1300 & 1300 \\
\hline Initial LP A & 100 & 100 & 1000 & 100 & 100 & 100 \\
\hline Initial LP B & 200 & 200 & 200 & 200 & 200 & 1200 \\
\hline net profit $A$ : & 0 & 650 & 0 & 0 & 0 & 0 \\
\hline net profit B: & 0 & 0 & 0 & 0 & 800 & 0 \\
\hline loss claimed A: & 0 & 0 & 0 & 300 & 300 & 300 \\
\hline loss claimed B: & 200 & 50 & 50 & 0 & 0 & 0 \\
\hline loss pool A: & 100 & 0 & 250 & 100 & 100 & 100 \\
\hline loss pool B: & 300 & 200 & 200 & 200 & 0 & 110 \\
\hline Firm $j$ & & & & & & \\
\hline Profit A: & -800 & -100 & -100 & 600 & 600 & 600 \\
\hline Profit B: & -300 & -300 & -300 & -800 & -300 & -300 \\
\hline Initial LP A & 100 & 100 & 100 & 100 & 100 & 1000 \\
\hline Initial LP B & 200 & 200 & 200 & 200 & 200 & 200 \\
\hline net profit A: & 0 & 0 & 0 & 5 & 200 & 0 \\
\hline net profit B: & 0 & 0 & 0 & 0 & 0 & 0 \\
\hline loss claimed A: & 0 & 100 & 100 & 0 & 0 & 0 \\
\hline loss claimed B: & 0 & 300 & 300 & 600 & 300 & 300 \\
\hline loss pool A: & 900 & 100 & 100 & 100 & 0 & 790 \\
\hline loss pool B: & 500 & 200 & 200 & 400 & 200 & 200 \\
\hline$\theta_{1}:$ & 0 & 0 & 0 & 0 & 0 & 0.65 \\
\hline$\theta_{2}:$ & 0 & 0 & 0 & 0 & 0 & 0 \\
\hline Cases exmined: & 0 & 0 & 0 & 21 & 0 & 41 \\
\hline
\end{tabular}


Table 15: Use of Losses: Cases 11 and 12

\begin{tabular}{lrrrrrr}
\hline \multicolumn{1}{c}{ Example: } & case 11 & & & case 12 & \\
Firm $i$ & & $(\mathrm{ii})$ & $(\mathrm{iii})$ & $(\mathrm{i})$ & $(\mathrm{ii})$ & $(\mathrm{iii})$ \\
Profit A: & -200 & -200 & -200 & -200 & -200 & -200 \\
Profit B: & 300 & 1300 & 1300 & 300 & 1300 & 1300 \\
Initial LP A & 100 & 100 & 100 & 100 & 100 & 100 \\
Initial LP B & 200 & 50 & 800 & 200 & 200 & 800 \\
net profit A: & 0 & 0 & 0 & 0 & 0 & 0 \\
net profit B: & 0 & 450 & 0 & 0 & 200 & 0 \\
loss claimed A: & 200 & 200 & 200 & 200 & 200 & 200 \\
loss claimed B: & 0 & 0 & 0 & 0 & 0 & 0 \\
loss pool A: & 100 & 100 & 100 & 100 & 100 & 100 \\
loss pool B: & 200 & 0 & 225 & 200 & 0 & 400 \\
& & & & & & \\
Firm $j$ & & & & & & \\
Profit A: & -800 & -800 & -800 & -400 & -400 & -400 \\
Profit B: & 300 & 300 & 300 & -300 & -300 & -300 \\
Initial LP A & 100 & 100 & 100 & 100 & 100 & 100 \\
Initial LP B & 200 & 100 & 200 & 200 & 200 & 200 \\
net profit A: & 0 & 0 & 0 & 0 & 0 & 0 \\
net profit B: & 0 & 0 & 0 & 0 & 0 & 0 \\
loss claimed A: & 400 & 800 & 800 & 0 & 400 & 400 \\
loss claimed B: & 0 & 0 & 0 & 100 & 300 & 300 \\
loss pool A: & 500 & 100 & 100 & 500 & 100 & 100 \\
loss pool B: & 200 & 0 & 175 & 400 & 200 & 200 \\
$\theta_{1}$ : & & & & & & \\
$\theta_{2}$ : & 0 & 0 & 0.275 & 0 & 0 & 0 \\
Cases exmined: & 0 & 0 & 0 & 0 & 0 & 0 \\
\hline & & 0 & 13 & 0 & 0 & 0 \\
\hline
\end{tabular}


(i) where only current losses are used to offset positive profits. Table 17 shows example (ii), where both current losses, and all available loss pools, can be used to offset positive profits. Table 18 shows example (iii), where all current losses, and a fraction of available loss pools, can be used to offset positive profits.

Case 2 (i) is relatively straightforward. With available profits less than available losses within the group, losses are allocated to the three gross profit sources in positive profit as shown, to reduce net profits (and hence tax liabilities) to zero. Some period $t$ losses are carried forward to $t+1$.

Case 2 (ii) is also relatively straight forward but now all current losses and past losses can be used. All past losses, $\mathrm{LP}_{t-1}$, are deducted. All current losses are also deducted and are allocated in the following order: first against profits within the same firm, second across firms within the same source $(A$ or $B$ ), third across firms and profit source. In Case 2 (ii) this means that $£ 250$ of losses are deducted from $i$ 's $A$ profits, leaving net $A$ profits of $£ 100$. All other net profits are reduced to zero.

Case 2 (iii) is more complex because not all past losses can be used as deductions in period $t$. However Table 18 shows that by setting $\theta_{1}=0.25$, and $\theta_{2}=0.625$, this allows all current losses to be used and the maximum past losses of $£ 4600$ are also used. Thus, all net profits are zero in period $t$ and the minimum losses are carried forward. To see this, consider the alternative where instead of firm $j$ 's $B$ losses being used to reduce firm $i$ 's $B$ profits by $£ 500$ and its $A$ profits by $£ 200$ (as shown), this is reversed. A reworking of the numbers in Table 18 readily shows that firm $i$ 's net $B$ profits, liable to tax, would now be $£ 100$ (all others are zero) and losses carried forward would sum to $£ 4700$. 
Table 16: Use of Losses: Case 2 (i)

\begin{tabular}{lcccc}
\multicolumn{1}{c}{ Firm $i$} & \multicolumn{2}{c}{ Firm j } \\
\hline \multicolumn{1}{c}{ Profits: } & A: & B: & A: & B: \\
& Trading & Non-trading & Trading & Non-trading \\
\hline 1. Gross Profit & 400 & 200 & 100 & $\mathbf{- 8 0 0}$ \\
[Loss pool:LP ${ }_{\mathrm{t}-1}$ ] & {$[500]$} & {$[100]$} & {$[50]$} & {$[50]$} \\
2. Less Cap. Allow & 0 & 0 & 0 & 0 \\
3. = 1. minus 2. & 400 & 200 & 100 & $\mathbf{- 8 0 0}$ \\
4. Less $\mathrm{L}_{\mathrm{t}}$ & $\mathbf{- 4 0 0} \leftarrow$ & $\mathbf{- 2 0 0}$ & $\mathbf{- 1 0 0}$ & - \\
5. Less LP & 0 & 0 & 0 & - \\
\hline 6. Net Profit & 0 & 0 & 0 & $\downarrow$ \\
7. [Loss Pool:LP & {$[500]$} & {$[100]$} & {$[50]$} & {$[150]$} \\
\hline
\end{tabular}

Table 17: Use of Losses: Case 2 (ii)

Firm $i$

Firm j

\begin{tabular}{|c|c|c|c|c|}
\hline Profits: & $\begin{array}{c}\text { A: } \\
\text { Trading }\end{array}$ & $\begin{array}{c}\mathrm{B}: \\
\text { Non-trading }\end{array}$ & $\begin{array}{c}\text { A: } \\
\text { Trading }\end{array}$ & $\begin{array}{c}\mathrm{B}: \\
\text { Non-trading }\end{array}$ \\
\hline 1. Gross Profit & 400 & 200 & 100 & -400 \\
\hline [Loss pool:LP $\left.\mathrm{LP}_{\mathrm{t}-1}\right]$ & [50] & [100] & [50] & [100] \\
\hline 2. Less Cap. Allow & 0 & 0 & 0 & 0 \\
\hline $3 .=1$. minus 2 . & 400 & 200 & 100 & -400 \\
\hline 4. Less $L_{t}$ & $-250 \leftarrow$ & -100 & -50 & - \\
\hline 5. Less $\mathrm{LP}_{\mathrm{t}-1}$ & -50 & -100 & -50 & - \\
\hline 6. Net Profit & 100 & 0 & 0 & 0 \\
\hline 7. [Loss Pool:LP & [0] & [0] & [0] & {$[100]$} \\
\hline
\end{tabular}


Table 18: Use of Losses: Case 2 (iii)

\begin{tabular}{lcccc}
\multicolumn{1}{c}{ Firm $i$} & \multicolumn{3}{c}{ Firm $j$} \\
\hline \multicolumn{1}{c}{ Profits: } & $\mathrm{A}:$ & $\mathrm{B}:$ & $\mathrm{A}:$ & $\mathrm{B}:$ \\
& Trading & Non-trading & Trading & Non-trading \\
\hline 1. Gross Profit & 1000 & 500 & 100 & $\mathbf{- 8 0 0}$ \\
[Loss pool:LP $\mathrm{t}_{-1}$ ] & {$[5000]$} & {$[200]$} & {$[100]$} & {$[100]$} \\
2. Less Cap. Allow & 0 & 0 & 0 & 0 \\
3. = 1. minus 2. & 1000 & 500 & 100 & $\mathbf{- 8 0 0}$ \\
4. Less $\mathrm{L}_{\mathrm{t}}$ & $\mathbf{- 2 0 0}$ & $\mathbf{- 5 0 0}$ & $\mathbf{- 1 0 0}$ & - \\
5. Less LP & -800 & 0 & 0 & - \\
\hline 6. Net Profit & 0 & 0 & 0 & 0 \\
7. [Loss Pool:LP $\mathrm{t}$ ] & {$[4200]$} & {$[200]$} & {$[100]$} & {$[100]$} \\
\hline & $\theta_{1}=0.25$ & $\theta_{2}=0.625$ & $\mathbf{1 - \theta _ { \Gamma } - \theta _ { 2 } = 0 . 1 2 5}$ \\
\hline
\end{tabular}

\section{References}

[1] Creedy, J. and Gemmell, N. (2004) The revenue responsiveness of income and consumption taxes in the UK. Fiscal Studies, 25, pp. 55-77.

[2] Creedy, J. and Gemmell, N. (2006a) Modelling Tax Revenue Growth. Cheltenham: Edward Elgar.

[3] Creedy, J. and Gemmell, N. (2006b) Corporation tax buoyancy and revenue elasticity in the UK.

[4] Creedy, J. and Gemmell, N. (2006c) The distribution of profits in the UK.

[5] Devereux, M.P., Griffith, R. and Klemm, A (2004) How has the UK corporation tax raised so much revenue? Fiscal Studies, 25, pp. 367-388.

[6] National Statistics (2005) The United Kingdom National Accounts. The Blue Book. Basingstoke: Palgrave Macmillan. 